\title{
Fast Biases in Monsoon Rainfall over Southern and Central India in the Met Office Unified Model
}

\author{
RICHARD J. KEANE \\ Met Office, Exeter, and School of Earth and Environment, University of Leeds, Leeds, United Kingdom \\ Keith D. Williams, Alison J. Stirling, And Gill M. Martin \\ Met Office, Exeter, United Kingdom \\ CATHRYN E. BIRCH AND DOUGLAS J. PARKER \\ School of Earth and Environment, University of Leeds, Leeds, United Kingdom
}

(Manuscript received 28 September 2018, in final form 21 June 2019)

\begin{abstract}
The Met Office Unified Model (MetUM) is known to produce too little total rainfall on average over India during the summer monsoon period, when assessed for multiyear climate simulations. We investigate how quickly this dry bias appears by assessing the 5-day operational forecasts produced by the MetUM for six different years. It is found that the MetUM shows a drying tendency across the five days of the forecasts, for all of the six years (which correspond to two different model versions). We then calculate each term in the moisture budget, for a region covering southern and central India, where the dry bias is worst in both climate simulations and weather forecasts. By looking at how the terms vary with forecast lead time, we are able to identify biases in the weather forecasts that have been previously identified in climate simulations using the same model, and we attempt to quantify how these biases lead to a reduction in total rainfall. In particular, an anticyclonic bias develops to the east of India throughout the forecast, and it has a complex effect on the moisture available over the peninsula, and a reduction in the wind speed into the west of the region appears after about 3 days, indicative of upstream effects. In addition, we find a new bias that the air advected from the west is too dry from very early in the forecast, and this has an important effect on the rainfall.
\end{abstract}

\section{Introduction}

The Indian summer monsoon is one of the most important weather systems in the world, producing a large majority of the annual rainfall for over a billion people. It is also one of the most difficult for general circulation models (GCMs) to simulate on a range of spatial and temporal scales. Although there is significant interannual variability in the monsoon, one of the largest difficulties is in simulating the correct amount of total monsoon rainfall on average over an extended period of many years. Most GCMs exhibit a significant climatological JuneSeptember dry bias when compared with observations, while several others conversely produce too much rainfall (Sperber et al. 2013).

The Met Office Unified Model (MetUM) is one of many GCMs with a dry bias over India in the summer

Corresponding author: Richard J. Keane, r.j.keane@leeds.ac.uk months (Walters et al. 2017). Levine and Turner (2012) showed that a significant contribution to this dry bias comes from sea surface temperature (SST) biases in the coupled model version of the MetUM (these biases being themselves caused by biases in the atmospheric component) and, indeed, coupled rainfall and SST biases play an important part in Indian summer monsoon errors for GCMs generally (Levine et al. 2013). However, Levine and Turner (2012) also conducted an experiment with an atmosphere-only version of the MetUM forced with SSTs derived from observations, and here some aspects of the dry bias were improved, but a significant part of it remained. Similar results have been obtained in various other studies (Ringer et al. 2006; Martin et al. 2010; Martin and Levine 2012; Bush et al. 2015; Johnson et al. 2016, 2017; Levine and Martin 2018), so it is clear that deficiencies in the atmospheric component of the MetUM play a significant part. Although the situation has improved as recent versions of 
the MetUM have been released, the Indian dry bias remains one of the most significant biases in the configuration in current operational use (Walters et al. 2017).

The nature of the MetUM Indian monsoon dry bias has been studied extensively, and various mechanisms have been put forward as potential causes. For example, Bush et al. (2015) showed that the dry bias is related to a wet bias over the equatorial Indian Ocean: when they increased the convective entrainment over this latter region, suppressing the rainfall there, it led to an increase in rainfall over the Indian Peninsula. Levine and Martin (2018) showed that an inability to correctly simulate low pressure systems leads to a reduction in rainfall over India, and that this effect is mitigated when running a regional simulation over India, with the boundary forcing (including remote precursors to low pressure systems) provided by analyses. However, in both of these studies the dry bias was not explained entirely by the phenomenon investigated, and it is clear that in its totality it is due to an interplay of various remote and local effects and a range of temporal and spatial scales.

The aforementioned studies refer to longer climate simulations, but forecasting the Indian summer monsoon is also challenging at shorter time scales appropriate to numerical weather prediction (NWP) (Ranade et al. 2014; Gadgil and Srinivasan 2012), and the MetUM also shows rainfall biases at NWP scales (Prakash et al. 2016; Mitra et al. 2013). Categorical yes/no forecasts of rainfall are generally good, but it is rather more difficult to produce good forecasts of rainfall amount (Joshi and Kar 2016; Kumar et al. 2017). Although it is possible to improve forecasts by combining models or using postprocessing such as bias correction (Joshi and Kar 2016; Mitra et al. 2011), it is still desirable for NWP to use an underlying GCM that captures the physics and dynamics of the monsoon as well as possible, for example, in order to continue to produce good forecasts as the climate changes.

Mitra et al. (2013) showed that the MetUM produces too little rainfall over much of India on a time scale of a few days for summer 2012, although this bias is still smaller than the day-to-day variability in rainfall being predicted. One aim of the present study is to evaluate NWP forecasts produced operationally using the MetUM for multiple years, and to investigate to what extent these forecasts exhibit the dry bias seen in longer climate runs with the same underlying GCM. This will give insight into whether the bias is caused by fast processes such as convection, or processes that evolve more slowly, such as the global-scale circulation, without requiring lengthy climate simulations or, indeed, any simulations beyond those that have been produced for operational purposes.
Such an investigation is made possible by the fact that the Met Office applies a "seamless" approach to predicting the weather and climate, whereby a single GCM is developed for all weather and climate time scales (Brown et al. 2012; Mitra et al. 2013). This has previously been exploited by Birch et al. (2014), to study the water cycle of the West African monsoon, and by Martin et al. (2010), who showed that two long-standing systematic errors (including in the Asian monsoon region), present in longer climate runs, appear during the first few days of NWP forecasts. Additionally, Bush et al. (2015) traced the influence of changing the entrainment parameter over the equatorial Indian Ocean region from the first few days of a simulation to the climate time scale. NWP techniques have also been used to assess climate models by Rodwell and Palmer (2007) and Klocke and Rodwell (2014), who used temporally averaged tendencies from the data assimilation system to represent fast errors in the model, and investigated their sensitivity to changes in model parameters.

In this paper we investigate how the MetUM dry bias develops within the first five days of the forecast, and carry out a detailed investigation of the moisture budget for a region covering southern and central India, within which the dry bias seems to look similar after 5 days to that after 30 years. This is shown in Fig. 1, which shows the rainfall bias for a 30-yr climate simulation against GPCP data (Adler et al. 2003) and for a series of NWP forecasts, of accumulation between 4.5 and 5 days (where forecasts were initialized every $12 \mathrm{~h}$, so the full diurnal cycle is captured here) against Tropical Rainfall Measuring Mission (TRMM) data (Huffman et al. 2007). As well as the dry bias within the green box, the significant wet bias over the equatorial Indian Ocean seen in the climate run is also seen in the weather forecasts, although the dry bias over northern India seen in the climate run is not seen in the weather forecasts. We investigate the operational forecasts for the period 2012-17 and show that, while the bias against observations is not always dry at early (1-2 day) forecast ranges, every year has a drying tendency from the start of the forecast such that the model is always too dry at five days. For the remainder of the paper, we therefore carry out a more detailed investigation of how the different terms in the moisture budget develop, in comparison with their values at analysis time. By confining this study to the drying tendency between the end and beginning of the forecast, we can make a direct comparison between later and earlier forecasts. This removes the need to provide observed values of the horizontal flux terms, which would require wind speed and humidity profile measurements at a large number of locations. 
(a) 30-year climate, absolute difference

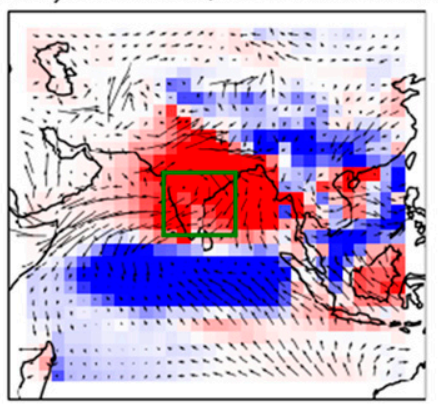

$2 \mathrm{~m} / \mathrm{s}-$ (b) 5-day NWP, absolute difference

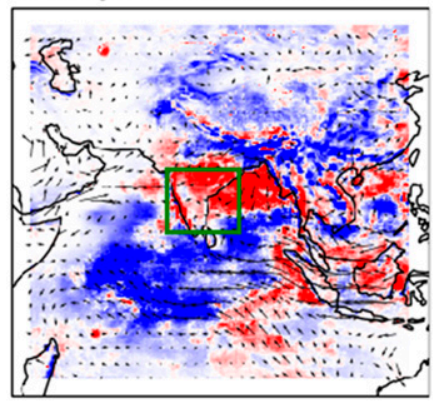

$2 \mathrm{~m} / \mathrm{s}-$ (c) NWP: $108-120$ hours minus $36-48$ hours

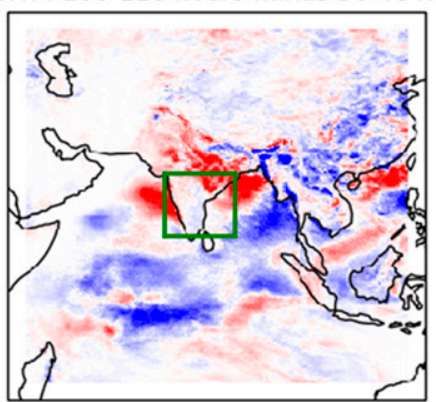

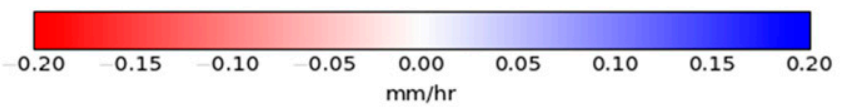

(d) 30-year climate, relative difference

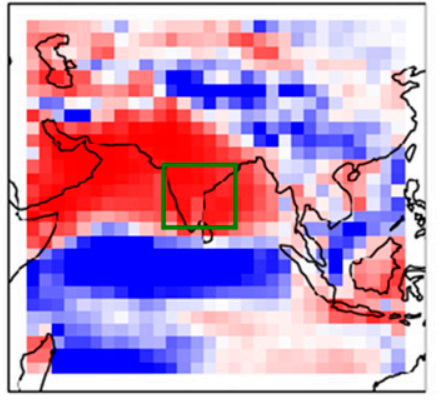

(e) 5-day NWP, relative difference
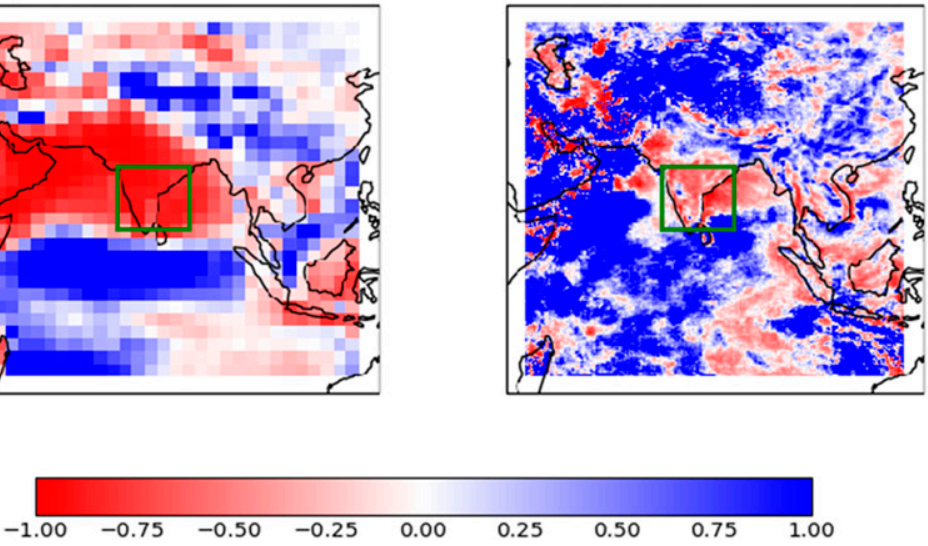

FIG. 1. (a),(d) Rainfall bias against GPCP rainfall data for a climate simulation for 1983-2012, using the MetUM version GA6, restricted to the months of June, July, and August. (b),(e) Rainfall bias against TRMM rainfall data for 3 months' worth of 5-day weather forecasts for June, July, and August 2012. (c) Rainfall difference between accumulation from 108 to $120 \mathrm{~h}$ and accumulation from 36 to $48 \mathrm{~h}$. (top) The rainfall difference itself and (bottom) the difference divided by the observed value. Panels (a) and (b) are overlaid with wind bias vectors at 850-hPa height [bias against ERA-interim reanalyses for (a) and against NWP analysis for (b)]. The green box is the evaluation region used in this study.

\section{Methods}

\section{a. Datasets}

In the first part of our investigation we analyze the forecasts produced operationally by the Met Office for June, July, and August for each of the six years 2012-17. Over this period, the MetUM has been initialized four times per day (at 0000, 0600, 1200, and 1800 UTC), but we restrict this part of the investigation to the forecasts starting at 0000 and 1200 UTC out to $120 \mathrm{~h}$, since the forecasts starting at 0600 and 1800 UTC were only produced up to $60 \mathrm{~h}$. The operational setup was upgraded during the 6-yr period, so the analysis covers more than one version of the MetUM. In 2012 the MetUM was run operationally in the Global Atmosphere 3.1 (GA3.1) configuration (Walters et al. 2011) at
$\mathrm{N} 512$ resolution $\left(37 \mathrm{~km}\right.$ at $\left.20^{\circ} \mathrm{N}\right)$. This was upgraded on 15 July 2014 to the GA6.1 configuration (Walters et al. 2017 ) at $\mathrm{N} 768$ resolution $\left(25 \mathrm{~km}\right.$ at $\left.20^{\circ} \mathrm{N}\right)$, and a further resolution upgrade was implemented on 12 July 2017 to $\mathrm{N} 1280\left(15 \mathrm{~km}\right.$ at $\left.20^{\circ} \mathrm{N}\right)$. The observational data we used for comparison were TRMM data (Huffman et al. 2007; Hou et al. 2014); the dataset used was 3B42, version 7 (Huffman et al. 2010).

For the moisture budget evaluation, which comprises most of our investigation, we use output from the forecasts produced operationally by the Met Office for 2012 . Here we use forecasts starting at all four available times. We use instantaneous (i.e., model time step) values of precipitation $P$, surface upward moisture flux $E$ and, defined on model levels, pressure $p$, specific humidity $q$, and horizontal wind $\mathbf{V}$. We also use surface latent heat 
flux $h$, defined as a 6-h mean, to calibrate the surface upward moisture flux (see appendix).

For both investigations, quantities have been averaged over forecasts initialized in June, July, and August. We have restricted to valid times from 6 June until 31 August-constant for each forecast lead time-so that for a perfect forecast each term should be independent of lead time. The evolution of the quantities with forecast lead time therefore gives an indication as to how quantities change as the forecast develops.

\section{b. Moisture budget calculation}

Following Yanai et al. (1973), Zangvil et al. (2001), and Zangvil et al. (2004) we write the moisture budget as

$$
\frac{1}{g} \frac{\partial}{\partial t} \iiint q d^{2} A d p=-\frac{1}{g} \int \oint_{A} q \mathbf{V} \cdot d \mathbf{l} d p+\iint(E-P) d^{2} A,
$$

where $g$ is the acceleration due to gravity, $t$ is time, $A$ is an arbitrary horizontal area, and $d \mathbf{l}$ is an element along the edge of $A$. Note that we do not define quantities as area averages, but apply an extra area integral compared with Zangvil et al. (2004). Note also that this budget applies to water vapor, so that storage of moisture in clouds, and horizontal transport of clouds, is neglected.

Applying this to a box region over India, bounded by latitudes $\left(\theta_{1}, \theta_{2}\right)$ (here equal to $9.02^{\circ}$ and $\left.21.45^{\circ} \mathrm{N}\right)$ and longitudes $\left(\phi_{1}, \phi_{2}\right)$ (here equal to $71.89^{\circ}$ and $85.96^{\circ} \mathrm{E}$ ), the first term on the right-hand side of Eq. (1) can be written

$$
\begin{aligned}
-\int \oint_{A} q \mathbf{V} \cdot d \mathbf{l} d p= & {\left[\int_{p=0}^{p=p_{\text {surface }}} \int_{\theta=\theta_{1}}^{\theta=\theta_{2}} q u r_{E} d \theta d p\right]_{\phi=\phi_{2}}^{\phi=\phi_{1}} } \\
& +\left[\int_{p=0}^{p=p_{\text {surface }}} \int_{\phi=\phi_{1}}^{\phi=\phi_{2}} q v r_{E} \cos \theta d \phi d p\right]_{\theta=\theta_{2}}^{\theta=\theta_{1}}
\end{aligned}
$$

and for an arbitrary quantity $x$ :

$$
\begin{aligned}
\iint x d^{2} A & =\int_{\theta=\theta_{1}}^{\theta=\theta_{2}} \int_{\phi=\phi_{1}}^{\phi=\phi_{2}} x r_{E}^{2} \cos \theta d \theta d \phi \\
& \equiv\langle x\rangle \times r_{E}^{2}\left(\sin \theta_{2}-\sin \theta_{1}\right)\left(\phi_{2}-\phi_{1}\right),
\end{aligned}
$$

where the angle brackets represent an area-weighted mean of the values at each grid box and $r_{E}$ is the radius of Earth.

We define the fluxes into the box on the western, eastern, southern and northern sides as, respectively,

$$
\begin{aligned}
& \mathbb{M}_{\mathrm{W}}=\left.\frac{r_{E}}{g} \int_{p=0}^{p=p_{\text {surface }}} \int_{\theta=\theta_{1}}^{\theta=\theta_{2}} q u d \theta d p\right|_{\phi=\phi_{1}}, \\
& \mathbb{M}_{\mathrm{E}}=-\left.\frac{r_{E}}{g} \int_{p=0}^{p=p_{\text {surface }}} \int_{\theta=\theta_{1}}^{\theta=\theta_{2}} q u d \theta d p\right|_{\phi=\phi_{2}}, \\
& \mathbb{M}_{\mathrm{S}}=\left.\frac{r_{E}}{g} \int_{p=0}^{p=p_{\text {surface }}} \int_{\phi=\phi_{1}}^{\phi=\phi_{2}} q v \cos \theta d \phi d p\right|_{\theta=\theta_{1}}, \quad \text { and } \\
& \mathbb{M}_{\mathrm{N}}=-\left.\frac{r_{E}}{g} \int_{p=0}^{p=p_{\text {surface }}} \int_{\phi=\phi_{1}}^{\phi=\phi_{2}} q v \cos \theta d \phi d p\right|_{\theta=\theta_{2}} .
\end{aligned}
$$

We define the total flux $\mathbb{E}$ of moisture entering the box from the surface and the total flux $\mathbb{P}$ of moisture leaving the box due to precipitation as

$$
(\mathbb{E}, \mathbb{P})=\iint(E, P) d^{2} A .
$$

So Eq. (1) can be rewritten as

$$
\mathbb{Q}_{t}=\mathbb{M}_{\mathrm{W}}+\mathbb{M}_{\mathrm{E}}+\mathbb{M}_{\mathrm{S}}+\mathbb{M}_{\mathrm{N}}+\mathbb{E}-\mathbb{P},
$$

where

$$
\mathbb{Q}_{t}=\frac{1}{g} \frac{\partial}{\partial t} \iiint q d^{2} A d p
$$

is the rate of change of total moisture in the box. We also define $\mathbb{M}_{A}=\mathbb{M}_{\mathrm{W}}+\mathbb{M}_{\mathrm{E}}+\mathbb{M}_{\mathrm{S}}+\mathbb{M}_{\mathrm{N}}+\mathbb{E}$ as the total net moisture flux entering the box, which is "available" for rainfall. We have multiplied each term in kilograms per second $\left(\mathrm{kg} \mathrm{s}^{-1}\right)$ by $3600 \mathrm{~s} \mathrm{~h}^{-1} / \iint d^{2} A$ and assumed a water density of $10^{3} \mathrm{~kg} \mathrm{~m}^{-3}$, to obtain a value that represents the amount of rainfall in millimeters per hour $\left(\mathrm{mm} \mathrm{h}^{-1}\right)$ that would be produced in the box if all the moisture from that term were converted into rainfall.

The moisture conservation of the MetUM can be tested by comparing $\mathbb{Q}_{t}$ and $\mathbb{M}_{A}-\mathbb{P}$, since both can be calculated directly from different model outputs. We take $\mathbb{Q}_{t}\left[\tau_{(n-1) / 2}\right] \approx\left[\mathbb{Q}\left(\tau_{n}\right)-\mathbb{Q}\left(\tau_{n-1}\right)\right] / \Delta \tau$, where $n$ represents the individual forecast lead times separated by $\Delta \tau=12 \mathrm{~h}$, and $\mathbb{Q}=1 / g \iiint q d^{2} A d p$. Any discrepancies between $\mathbb{Q}_{t}$ and $\mathbb{M}_{A}-\mathbb{P}$ would suggest a lack of moisture conservation, although could also be caused by the somewhat coarse temporal discretization used to define $\mathbb{Q}_{t}$.

\section{c. Separation into moisture and wind effects}

The variation in the terms $\mathbb{M}_{\text {WESN }}$ could be due to variations in the humidity, variations in the wind advecting the moisture, or a combination of the two. Here we separate the effects of the humidity field and of the wind field, by alternately only allowing one of the two to 
vary with forecast lead time. First, we define the terms in general as a function of forecast lead time $\tau$ :

$\mathbb{M}\{\tau\} \equiv \lambda\left\langle\int M\{\tau\} d p\right\rangle_{\Phi, t} \equiv \frac{\lambda}{g}\left\langle\int q\{\tau\} V\{\tau\} d p\right\rangle_{\Phi, t}$

where the angle brackets are here an average over forecast valid time, and the relevant latitude or longitude line $\Phi$ (representing $\theta$ or $\phi$ as appropriate), and $\lambda$ is the length of this line. The quantity $V$ represents the appropriate horizontal wind $u$ or $v$. Any changes in $\mathbb{M}$ could be due to changes in moisture $q$ or wind speed $V$ or the interaction thereof. It is interesting to isolate the effects of changing only $q$ or only $V$, and this is accomplished by defining

$$
\begin{aligned}
& \mathbb{H}\{\tau\} \equiv \lambda\left\langle\int H\{\tau\} d p\right\rangle_{\Phi, t} \equiv \frac{\lambda}{g}\left\langle\int q\{\tau\} V\{0\} d p\right\rangle_{\Phi, t} \\
& \mathbb{S}\{\tau\} \equiv \lambda\left\langle\int S\{\tau\} d p\right\rangle_{\Phi, t} \equiv \frac{\lambda}{g}\left\langle\int q\{0\} V\{\tau\} d p\right\rangle_{\Phi, t} .
\end{aligned}
$$

In this way, $\mathbb{H}$ represents how the moisture flux develops with forecast lead time, based only on variation in humidity (i.e., holding wind speed constant), and $\mathbb{S}$ represents how the moisture flux develops with forecast lead time based only on variation in wind speed (i.e., holding humidity constant).

In practice, quantities are defined on model levels, so we use the pressure field to define $d p / d z$ and integrate with respect to height $z$, from the surface up to approximately $18 \mathrm{~km}$. We take $d p / d z$ to vary with forecast lead time in the definition of $\mathbb{H}$ and to be constant in the definition of $\mathbb{S}$. The physical justification for this is that $d p / d z \approx-\rho g$, where $\rho$ is air density, so that

$$
\begin{aligned}
& \mathbb{H}\{\tau\} \approx \lambda\left\langle\int \rho\{\tau\} q\{\tau\} V\{0\} d z\right\rangle_{\Phi, t}, \quad \text { and } \\
& \mathbb{S}\{\tau\} \approx \lambda\left\langle\int \rho\{0\} q\{0\} V\{\tau\} d z\right\rangle_{\Phi, t},
\end{aligned}
$$

with the integration limits suitably reversed. The quantity $\rho q$ is the actual moisture content, so that $\mathbb{H}$ represents the variation in $\mathbb{M}$, varying only the moisture content, and $\mathbb{S}$ represents the variation in $\mathbb{M}$, varying only the wind speed.

\section{Results}

As mentioned in section 1 , there are similarities and differences in the rainfall bias between the climate simulation and weather forecasts produced using the
MetUM, as shown in Fig. 1. In this study, we focus on southern India, since both biases look similar here, so analyzing the bias in the weather forecasts could also provide insights into the bias in the climate simulation.

Figure 1 also shows vectors for the bias in wind speed at $850-\mathrm{hPa}$ height. These were calculated by taking a temporal mean over June, July, and August (for 19832012 for the climate simulations and 2012 for the NWP forecasts) and comparing with a reference dataset. The reference dataset for the climate simulations is ERAInterim (Dee et al. 2011) and for the NWP forecasts is the NWP analysis field.

Also shown in Fig. 1 is the relative difference in rainfall between model and observations, for both the weather forecasts and climate simulations. This is simply the actual difference divided by the relevant observed value (GPCP data for the climate simulation and TRMM data for the weather forecasts). This shows that the relative bias is somewhat lower for the weather forecasts than for the climate simulations. However, over the region chosen for this study, the dry bias is significant for both setups.

It is interesting to note that the dry bias in the weather forecasts does not seem to extend as far north as that in the climate simulation (cf. Figs. $1 \mathrm{a}$ and 1b). On further investigation, it was found that the rainfall over northern India increases during the first two days of the weather forecast and then decreases steadily thereafter. This can be seen from Fig. 1c, where there is a clear drying over northern India between two and five days, similar to that seen over southern India over the full five days. It may be the case, then, that the behavior over northern India after an initial two-day adjustment is similar to that over southern India. However, because this study attempts to use the first five days of the weather forecast to better understand the climate bias, we concentrate on the region in the green box shown in Fig. 1 for the rest of this study. Although the region of India to the north of the box is socioeconomically very important, and accounts for a large part of the total monsoon rainfall over India, we concentrate here on southern and central India so as to obtain a clear monotonic drying that develops over the full five days of the operational forecast being considered.

\section{a. General rainfall climatology}

Figure 2 shows the evolution of the total rainfall, within the green box in Fig. 1, as a function of forecast lead time, for the years 2012-17. The values are 12-h accumulations, and each accumulation is plotted against the whole period to which it applies. Also plotted is the observed rainfall for the same area, for which there is a single value independent of forecast lead time since the forecast valid time does not change. 

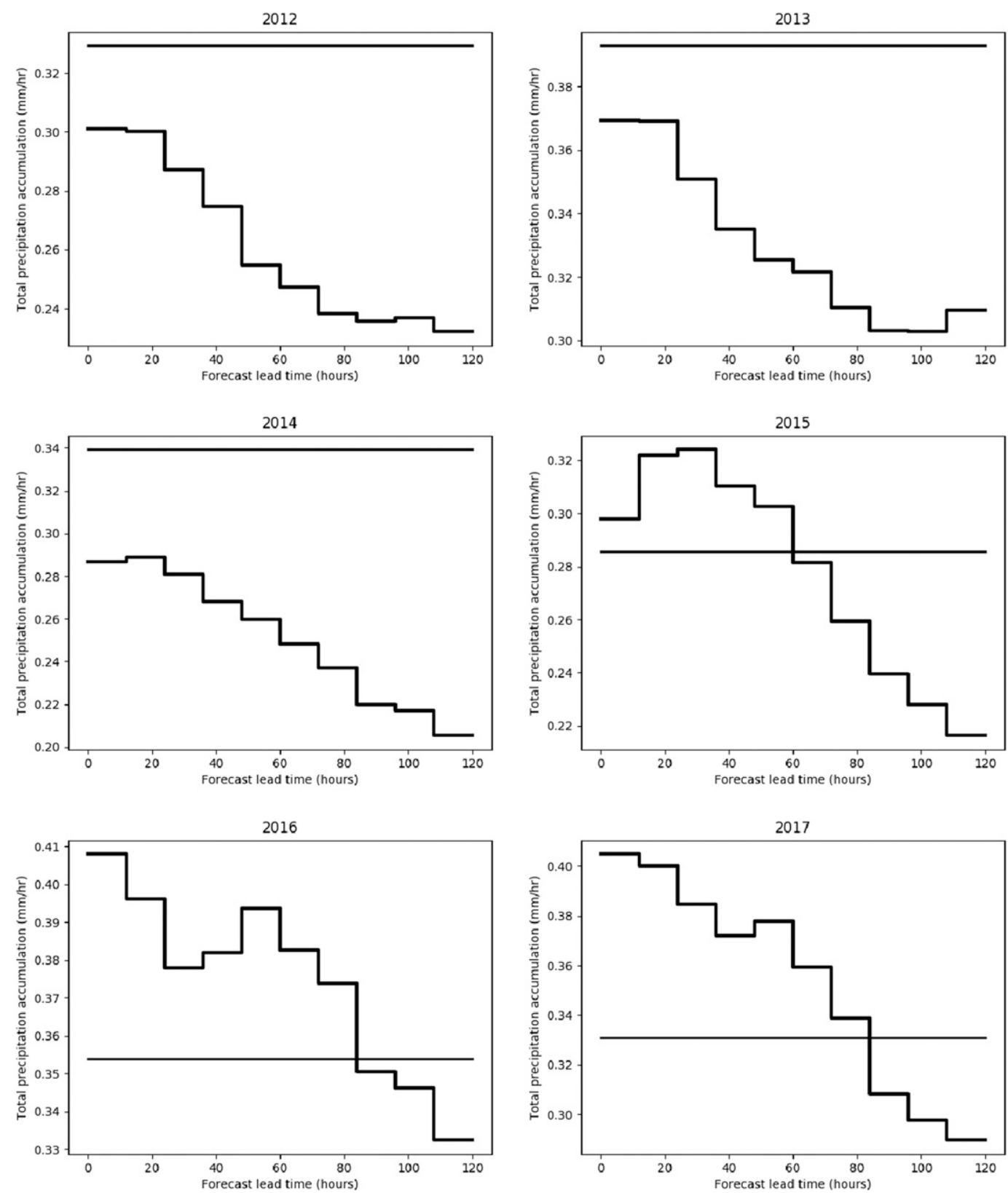

FIG. 2. The 12-h accumulated rainfall in the green box shown in Fig. 1, for June, July, and August of six different years, as a function of forecast lead time (thick lines) and observed (thin lines). The values have been converted to $\mathrm{mm} \mathrm{h}^{-1}$. Although the direction of the bias of the forecast against the observations varies, all six years show a drying tendency as the forecast develops.

Although the forecast rainfall bias is positive compared with observations for some years at some lead times, all years exhibit a drying tendency from the start of the forecast to 5 days so that the bias against observations is always negative after 5 days. This reduction is largely monotonic, although there is some increase in rainfall earlier in the forecast, particularly for 2015 and 2016. The upgrade in model version that took place in
2014 coincides with a shift from an initial dry bias to an initial wet bias, but both versions clearly show a drying tendency over 5 days.

Figure 3 shows how the bias in the climate simulation, shown in Fig. 1a, varies from year to year, for the same green box in Fig. 1. Although there is of course much variability, reflecting the different meteorological conditions in each year, there is no clear general trend in the behavior. 


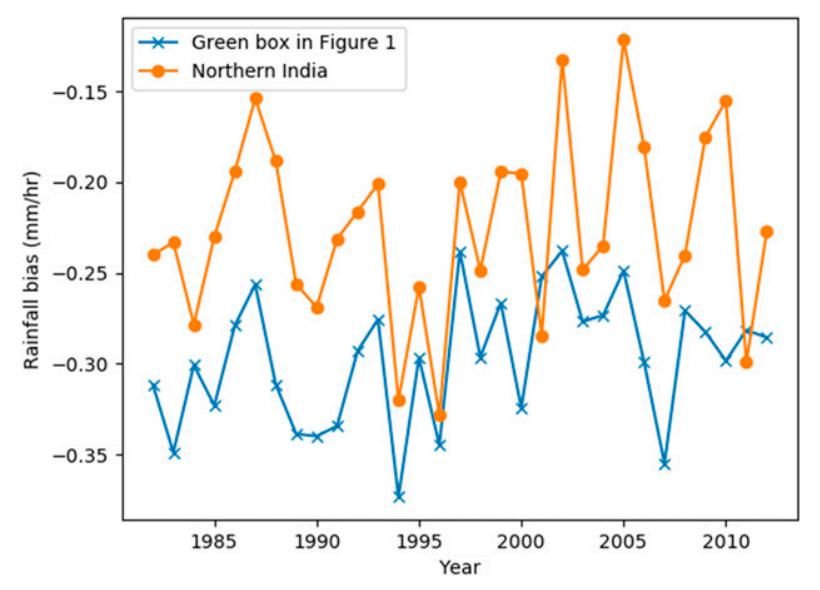

FIG. 3. Rainfall bias averaged over the green box shown in Fig. 1, and a region over northern India, for a MetUM climate simulation against GPCP rainfall data. Values are averaged over June, July, and August for each year. The regions are both bounded by longitudes $71.89^{\circ}$ and $85.96^{\circ} \mathrm{E}$. The green box is bounded by latitudes $9.02^{\circ}$ and $21.45^{\circ} \mathrm{N}$, and the region over northern India is bounded by latitudes $21.45^{\circ}$ and $28.95^{\circ} \mathrm{N}$.

The same is seen for northern India, suggesting that, for both regions, the dry bias develops quickly within the climate simulation, and then is a permanent feature of it.

These results suggest that an insight into the dry bias over India can be achieved by looking at the development of the forecast and how the bias compares at later and earlier lead times. For the rest of this study we therefore restrict the investigation to model fields (including the model analysis field), in order to investigate the first few days of its drying tendency. We also restrict the rest of the study to 2012, since it displays a clear monotonic drying tendency in rainfall and, given that this drying is robust over the full 6-yr period investigated, it would be expected that the conclusions drawn in the rest of the study would apply broadly to other recent years.

\section{b. Evaluation of moisture budget for 2012}

The moisture flux terms are plotted, as a function of lead time, in Fig. 4. The general behavior is that there is a steady decrease in rainfall $\mathbb{P}$ alongside a decrease in total available moisture $\mathbb{M}_{A}$ from advection and evaporation. Overall, there is a roughly constant moisture flux $\mathbb{E}$ at the surface, which is lower than $\mathbb{P}$, suggesting that the net reduction in rainfall is driven by moisture advection changes. The budget is characterized by a strong westerly flow, so $\mathbb{M}_{\mathrm{W}}$ and $\mathbb{M}_{\mathrm{E}}$ are much greater in magnitude than the other terms. We have therefore subtracted $1 \mathrm{~mm} \mathrm{~h}^{-1}$ from the westerly and easterly flow components (leaving no net effect on the budget) in Fig. 4 for clarity. It is clear that the flow from the western, northern, and southern sides of the box are net sources of moisture in the model, with the flow from the eastern side a net sink of moisture (i.e., net flow out of the box).

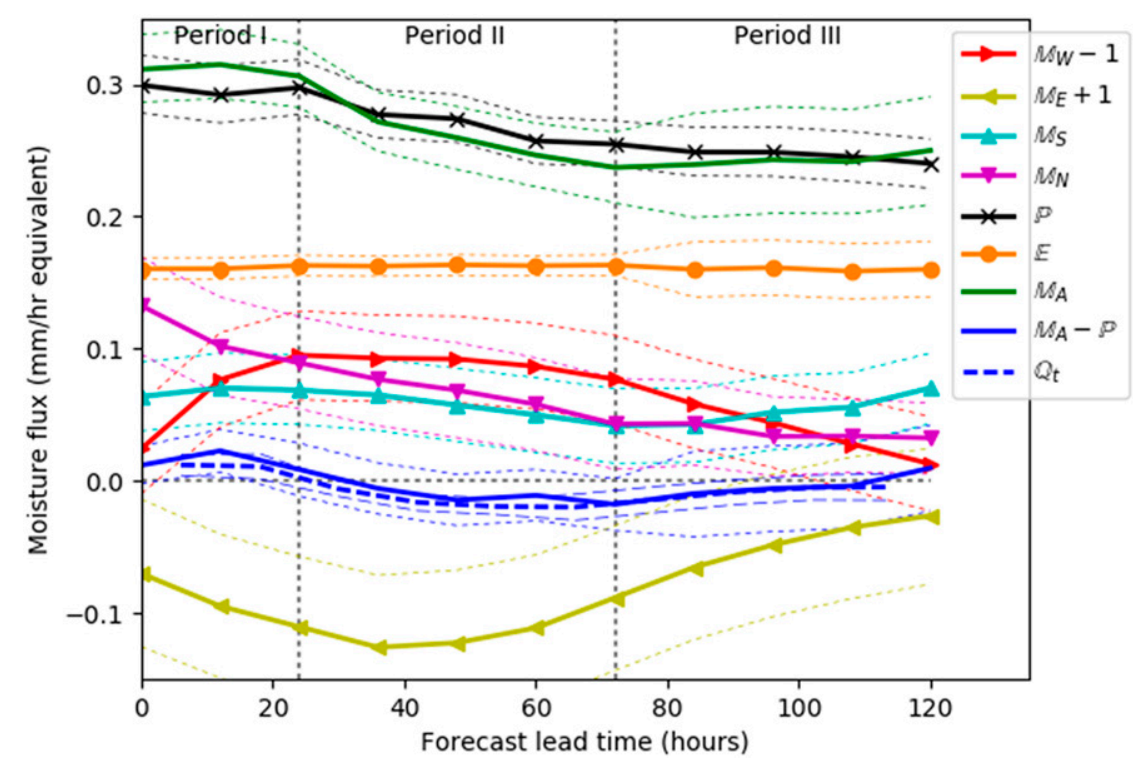

FIG. 4. Behavior of each of the moisture budget terms as a function of forecast lead time. An offset of $1 \mathrm{~mm} \mathrm{~h}^{-1}$ equivalent westerly flux has been removed. The precipitation $\mathbb{P}$ follows the "available" moisture $\mathbb{M}_{A}$, and the budget is approximately balanced (blue lines near zero). The vertical gray dotted lines identify the three periods defined in the text, for each of which the behavior of the moisture budget terms seems to fit into one of three coherent regimes. The thin dotted lines show the $95 \%$ confidence interval for the quantity shown in the same color. 


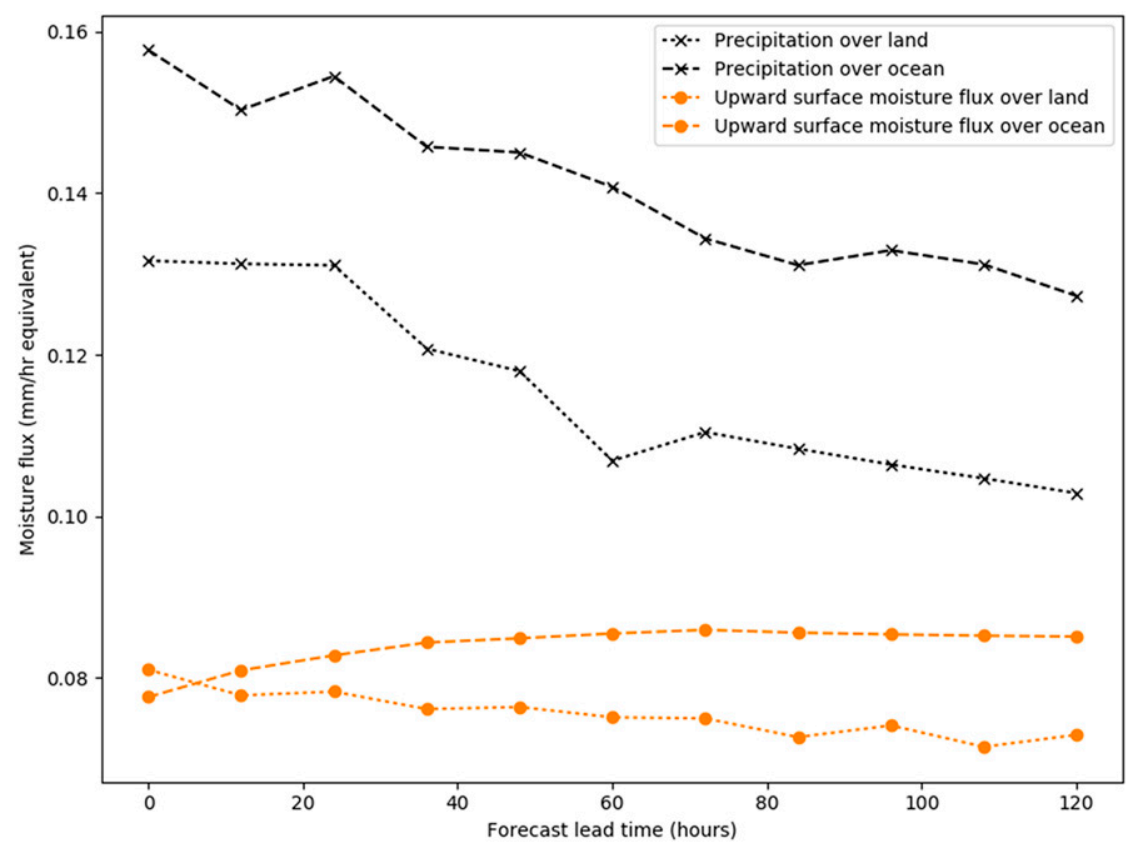

FIG. 5. Behavior of upward surface water flux and precipitation as a function of forecast lead time, restricted to land points only (dotted lines) and ocean points only (dashed lines).

The actual values of $\mathbb{Q}_{t}$ and $\mathbb{M}_{A}-\mathbb{P}$ are approximately zero at $\tau=0$ (although significantly above, rather than below, zero), indicating that the moisture in the box is fairly constant from one analysis to the next over the 3 -month period. They are also approximately equal to each other, suggesting that the MetUM keeps an approximately balanced moisture budget (relative to the magnitude of the tendencies) for the duration of the forecast. The variation in $\mathbb{M}_{A}, \mathbb{P}$, and $\mathbb{Q}_{t}$ can be broadly divided into three stages. During the first day of the forecast (which we define as period I), $\mathbb{M}_{A}$ and $\mathbb{P}$ are approximately constant, with $\mathbb{M}_{A}$ slightly larger than $\mathbb{P}$ so that there is a moistening of the box during this period; although the significance interval allows for some possibility of $\mathbb{P}$ being larger than $\mathbb{M}_{A}$, $\mathbb{Q}_{t}$ is significantly positive. From days 1 to 3 (period II), both quantities decrease, but $\mathbb{M}_{A}$ decreases rather faster. Again, the significance intervals suggest that this will vary depending on the precise period used for the calculation, but $\mathbb{Q}_{t}$ is significantly negative, suggesting a drying of the box during this period. From days 3 to 5 (period III), $\mathbb{M}_{A}$ levels off and even increases slightly, while $\mathbb{P}$ continues to decrease so that the box continues to dry but at a slower and slower rate, until at day 5 the budget becomes approximately balanced (here $\mathbb{Q}_{t}$ is significantly negative at the start of the period, but approaches zero toward the end of the period).

The zonal moisture advection also seems to follow a three-stage pattern, as $\mathbb{M}_{\mathrm{W}}$ and $\mathbb{M}_{\mathrm{E}}$ both increase in magnitude during period I, start to reduce slowly in magnitude during period II, and then reduce more quickly in magnitude during period III. The flow into the south of the box $\mathbb{M}_{S}$ varies rather less (following a similar pattern to $\mathbb{Q}_{t}$ ), and the flow into the north of the box $\mathbb{M}_{\mathrm{N}}$ decreases monotonically throughout the forecast, although this decrease is slower during period III than during the other periods.

Figure 4 suggests that the fastest processes during the first day of the forecast do not contribute immediately to the reduction in rainfall, and are likely due to model spinup and adjustment to analysis, but that the processes on time scales of a few days do make a significant contribution.

Figure 5 shows the separation of $\mathbb{P}$ and $\mathbb{E}$ into land and ocean components. It can be seen that the steady reduction in $\mathbb{P}$ occurs over both land and ocean, and roughly to the same extent. The behavior of $\mathbb{E}$ is, however, different over land and over ocean. Over ocean it increases at the beginning of the forecast and seems to approach an asymptotic value, while over land there is a steady decrease, although this is much less pronounced than the decrease in $\mathbb{P}$. The effects over land and ocean cancel each other somewhat, leading to the approximately constant value of $\mathbb{E}$ with lead time over the region as a whole.

\section{c. Separation into components}

Figure 6 shows the variation in the total horizontal moisture flux (the sum of the individual horizontal flux 


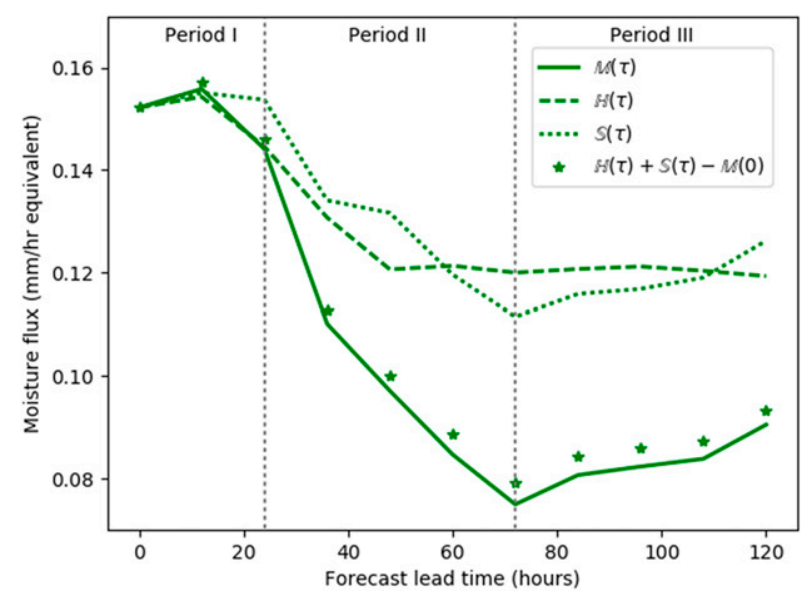

FIG. 6. Total horizontal flux $\mathbb{M}$ (solid line) into the green box in Fig. 1, with separation into variation due to humidity changes $\mathbb{H}$ (dashed line) and variation due to horizontal wind changes $\mathbb{S}$ (dotted line). Also plotted is the variation due to these individual components added together (stars; $\mathbb{M}\{0\}+\mathbb{H}\{\tau\}-\mathbb{H}\{0\}+\mathbb{S}\{\tau\}-\mathbb{S}\{0\}$ ).

terms, equal to $\mathbb{M}_{A}-\mathbb{E}$ ) and its components $\mathbb{H}$ (which represents the evolution with forecast lead time due to humidity changes only) and $\mathbb{S}$ (which represents the evolution with forecast lead time due to wind speed changes only). The term $\mathbb{S}$ is constant during period I and reduces throughout period II before increasing slightly during period III. The term $\mathbb{H}$ follows a similar pattern, but starts to decrease earlier during period I, and also stops decreasing earlier during period II.

Also plotted is $\mathbb{M}\{0\}+(\mathbb{H}\{\tau\}-\mathbb{H}\{0\})+(\mathbb{S}\{\tau\}-\mathbb{S}\{0\})=$ $\mathbb{H}\{\tau\}+\mathbb{S}\{\tau\}-\mathbb{M}\{0\}$, which represents the sum of the variation due to wind and the variation due to moisture, without any interaction between the two. This is approximately equal to $\mathbb{M}$, suggesting that the errors in the two quantities do not interact, and that investigating the errors in $\mathbb{H}$ and $\mathbb{S}$ individually is sufficient to understand the overall errors.

Figure 7 shows the variation in the individual horizontal flux terms $\mathbb{M}$ (as in Fig. 4, but with no offset removed), and their components $\mathbb{H}$ and $\mathbb{S}$. It is clear that, for the three terms other than $\mathbb{M}_{\mathrm{W}}$, the variation is driven almost completely by the wind speed, with the humidity having a minimal effect on the evolution with forecast lead time. The reduction in $\mathbb{H}$ seen in Fig. 6 is driven almost entirely by a reduction in humidity entering the box from the west. The behavior of $\mathbb{S}$ in Fig. 6 during period II seems to be driven principally by a reduction in wind speed into the northern edge of the box, whereas the behavior during period III is complicated, with the inflow to the north and west decreasing, the inflow to the south increasing and the outflow to the east decreasing.
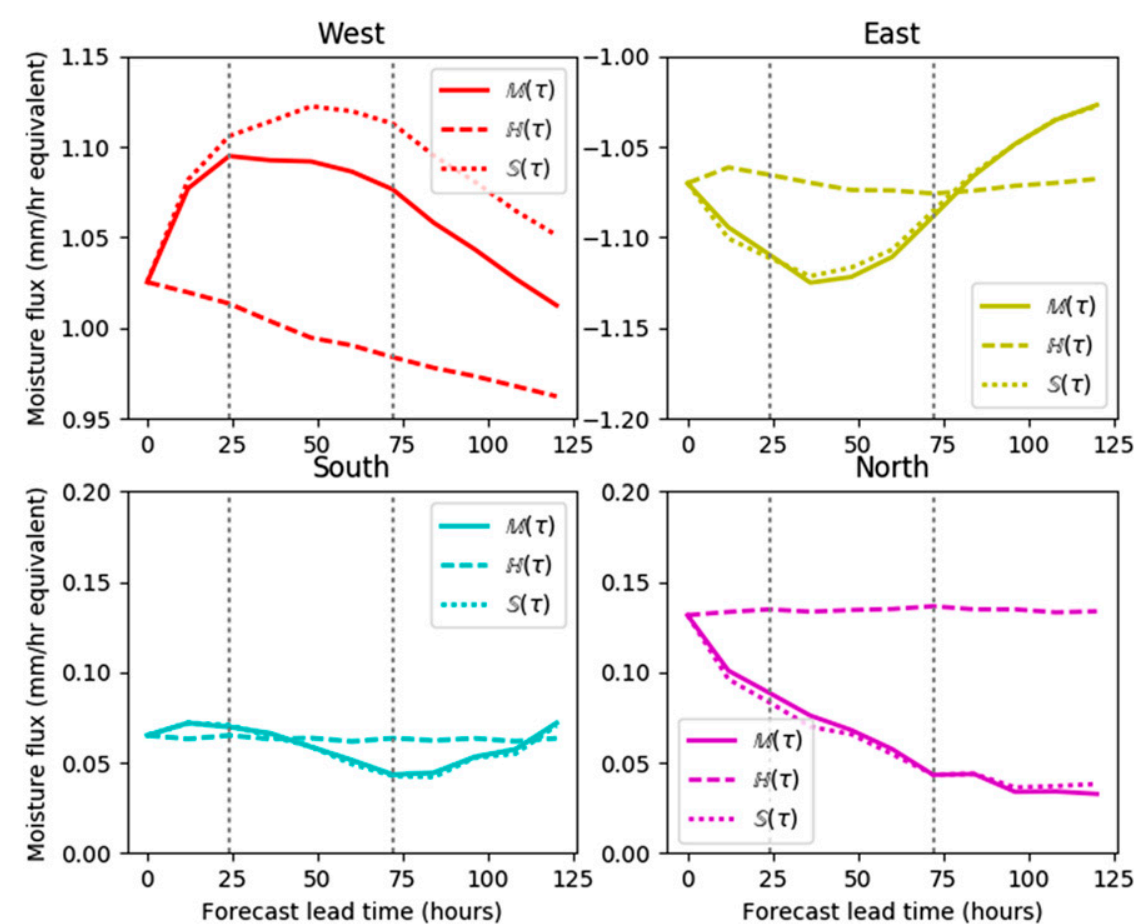

FIG. 7. Separation of the individual horizontal flux terms $\mathbb{M}$ into variation due to humidity changes $\mathbb{H}$ and variation due to horizontal wind changes $\mathbb{S}$. The variation in each term is dominated by the horizontal wind changes, except for the western side of the box where the humidity changes have a significant effect. 

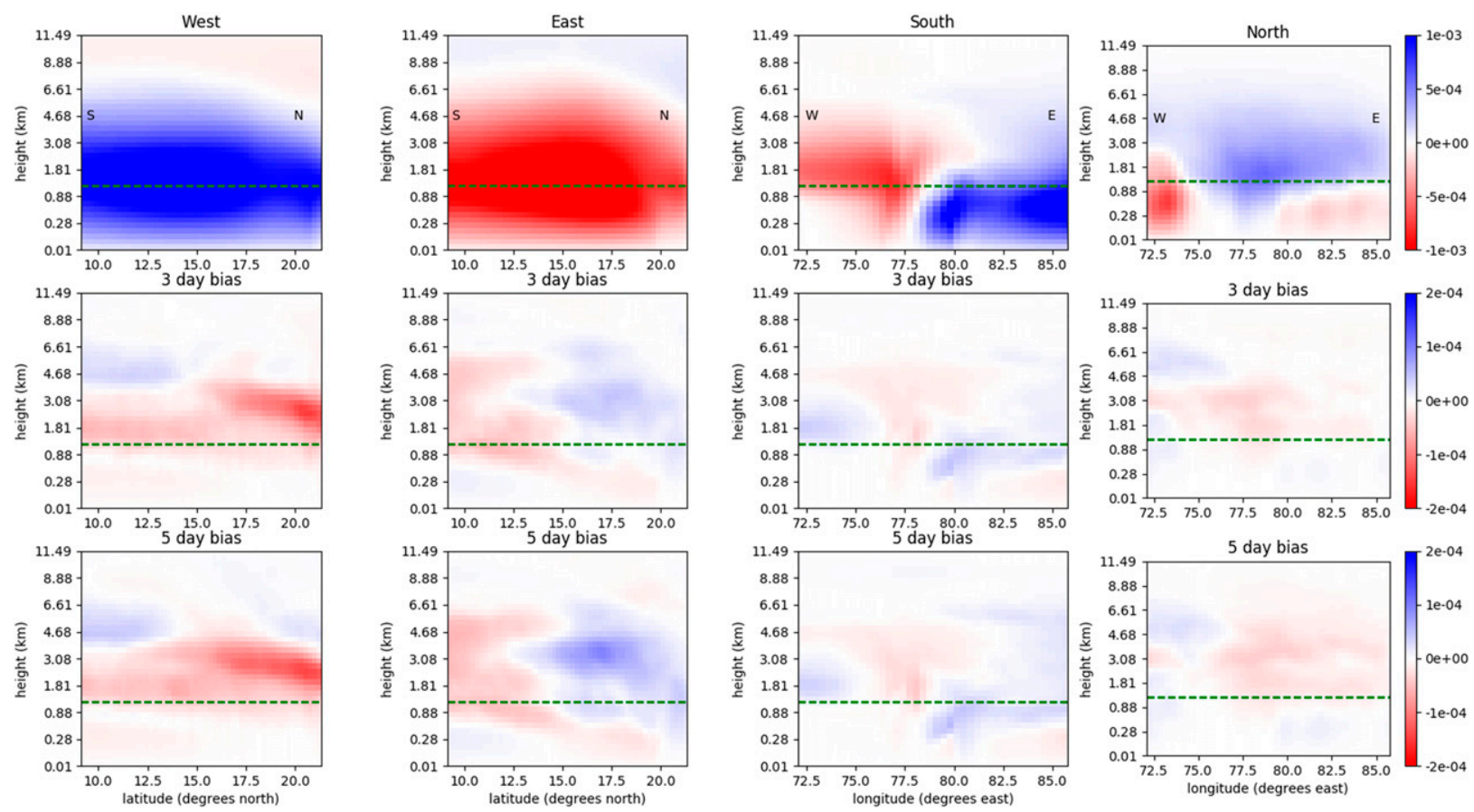

FIG. 8. Spatial variation of $H d p$ (horizontal moisture flux into box, with variation due to humidity only). Quantities are plotted at (top) analysis time, along with the bias against analysis after (middle) 3 days (corresponding to the end of period II) and (bottom) 5 days (corresponding to the end of period III). The quantity $q V(d p / d z) \delta z$ is converted into a $\mathrm{mm} \mathrm{h}^{-1}$ equivalent by multiplying by $(3600 / A) \delta l$, where $\delta l$ is the length of each grid element (constant for each panel, but different for each of the four directions). In this way, each pixel of a given color contributes equally to the total amount of moisture entering or leaving the box. Note that the color bar is set up so that blue always represents flow into the box, or a net increase in flow into the box, and red always represents flow out of the box, or a net decrease in flow into the box. The horizontal dashed green line represents the height $z_{b}=1.1 \mathrm{~km}$ identified in the text.

\section{d. Spatial variation of horizontal flux terms}

Figures 8 and 9 show the spatial variation of $H d p\{\tau\}$ and $S d p\{\tau\}$, respectively, in both the horizontal and vertical. These quantities refer to (respectively) $\mathbb{H}$ and $\mathbb{S}$ without the spatial average in Eqs. (13) and (14) but with the average over all the forecasts during the period 6 June-31 August. The top row in each figure shows the analysis field, which is the same for both figures because $H d p\{0\}=S d p\{0\}=M d p\{0\}$; blue colors here represent flow into the box and red colors represent flow out of the box. The middle rows show the bias that accumulates during periods I and II combined, and the bottom rows show the bias that accumulates during all three periods; here blue colors represent either an increase in flow into the box or a decrease in flow out of the box, and red colors represent either a decrease in flow into the box or an increase in flow out of the box.

The predominantly westerly flow into the western side and out of the eastern side of the box is clearly seen, and occurs throughout the depth and width of both of those two box sides. The flow at the southern side of the box has more variation in the horizontal, and seems to be cyclonic, although this in fact represents an undulation in the westerly flow so that it is northwesterly in the western half of the southern side, and southwesterly in the eastern half of the southern side, as will be discussed in a later subsection. The flow at the northern side of the box varies more in the vertical, with predominantly an inflow above $z_{b}=1.1 \mathrm{~km}$, and more variation below $z_{b}$. We have defined $z_{b}=1.1 \mathrm{~km}$ subjectively as a height that demarcates the flow (and its bias) into separate regimes; this height could be interpreted physically as roughly representing the depth of the boundary layer.

The spatial structure of the variation of $H d p$ (due to humidity changes) with forecast lead time is relatively simple. There is a decrease in the westerly inflow of moisture, which becomes greater with forecast lead time, and this decrease occurs mainly above $z_{b}$. There is a corresponding, but much smaller, decrease in the outflow of moisture from the eastern side of the box. The variation in the other terms is rather small.

The spatial structure of the variation of $S d p$ (due to wind speed changes) with forecast lead time is more complicated. The bias during periods I and II is that the westerly flow (into the western side and out of the eastern side) has strengthened, although some parts of the eastern side of the box show a reduction in the flow 

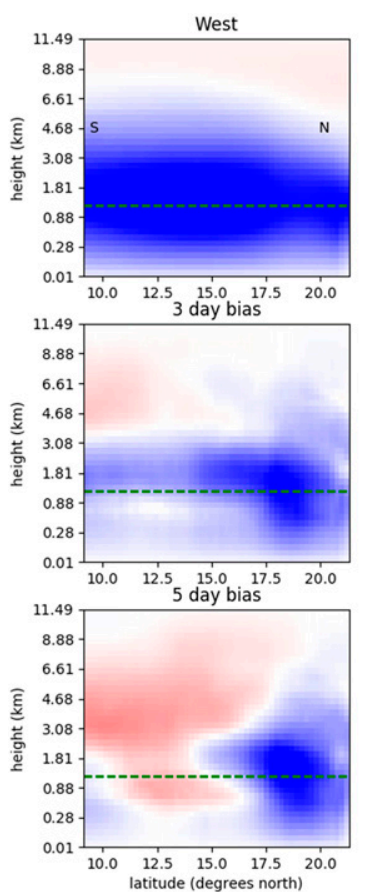
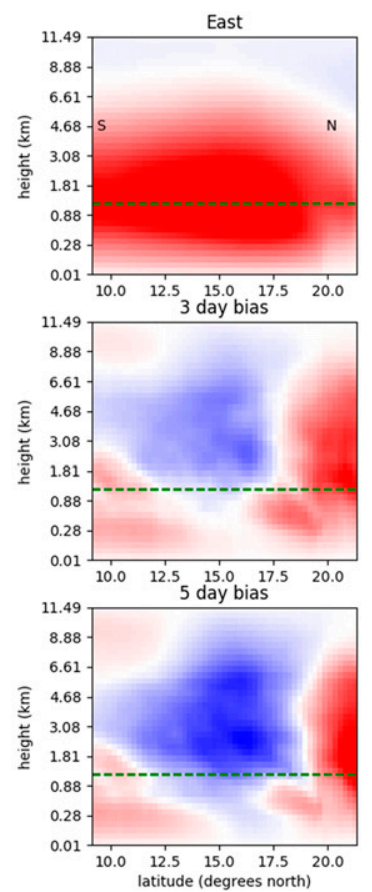
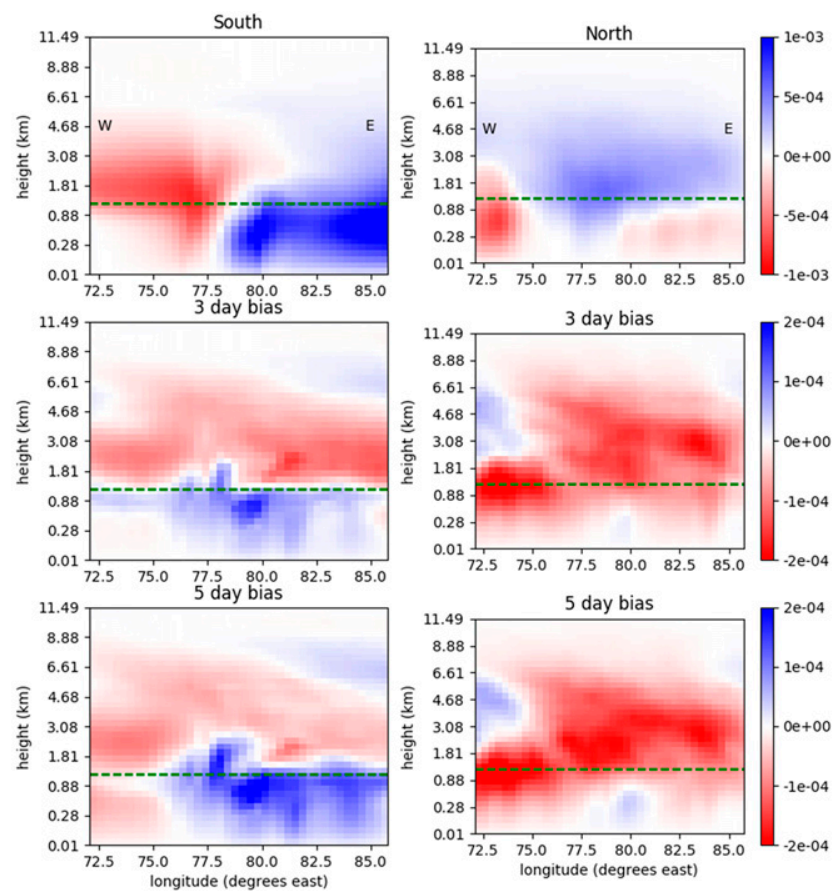

FIG. 9. Spatial variation of $S d p$ (horizontal moisture flux into box, with variation due to wind speed only). See caption of Fig. 8 for details.

out of the box. The flow into the box at the southern side increases below $z_{b}$ and decreases above $z_{b}$. The flow into the box at the northern side is almost uniformly reduced. Many of these effects are due to an anticyclonic bias, which will be discussed in a later subsection.

The variation of $S d p$ continues in a similar way through period III, except that the westerly flow is now weaker than it was at the end of period II. The flow into the box from the southwest starts to reduce; this represents a significant departure from the behavior during periods I and II.

Because $S d p$ displays significant biases both above and below $z_{b}=1.1 \mathrm{~km}$, we show $\mathbb{S}$ for the sum of fluxes in all directions in Fig. 10. We define $\mathbb{S}^{l}$ from Eq. (16) with the upper vertical integration limit set to $z=z_{b}$ (i.e., restricting to quantities below $z_{b}$ ), and $\mathbb{S}^{u}$ from Eq. (16) with the lower vertical integration limit set to $z=z_{b}$ (i.e., restricting to quantities above $z_{b}$ ). Figure 10 shows that the flux above $z_{b}$ decreases fairly monotonically with forecast lead time, although the decrease has essentially stopped by the end of period II. The flux below $z_{b}$ increases during period I, decreases during period II, and then increases slightly during period III. It is possible that the behavior early in the forecast is due to spinup effects, since the winds near the surface are likely to be more affected by the observations going into the analysis.

\section{e. Horizontal structure of humidity field and biases}

In Fig. 11 we show how the bias in the humidity develops with forecast lead time. There is a large dry bias to the northwest of India, which is present from day 1 and increases further as the forecast develops. It is also apparent that the air being advected over India from the west becomes increasingly too dry. These two effects are responsible for the reduction in $\mathbb{H}$ with forecast lead time seen in Fig. 6.

Parker et al. (2016) showed that the Indian monsoon is characterized by a competition between moist flow advected over the Indian Ocean from the southwest and dry air advected over the arid land from the northwest. These "dry intrusions" from the northwest

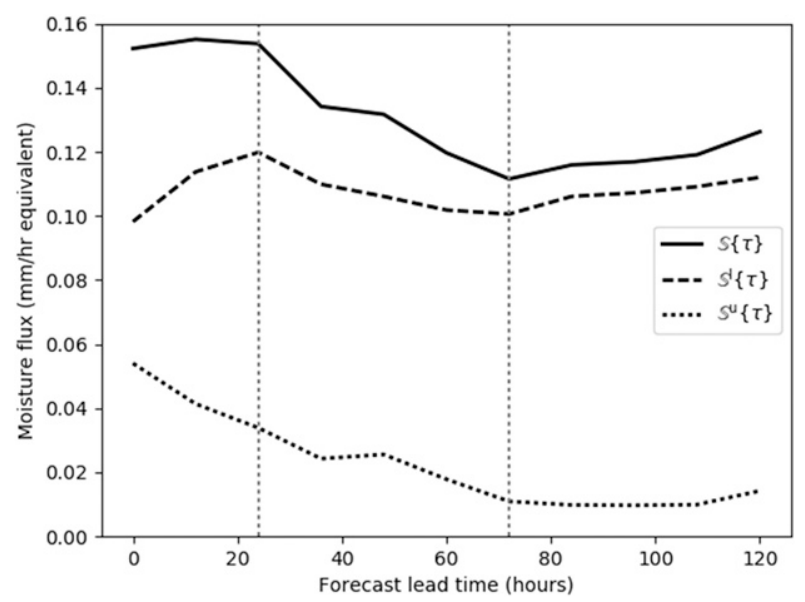

FIG. 10. Total horizontal moisture flux with variation due to wind speed $\mathbb{S}$ only (solid line), with separation into flux $\mathbb{S}^{l}$ below $z_{b}=$ $1.1 \mathrm{~km}$ (dashed line) and $\mathbb{S}^{u}$ above $z_{b}$ (dotted line). 
(a) Analysis

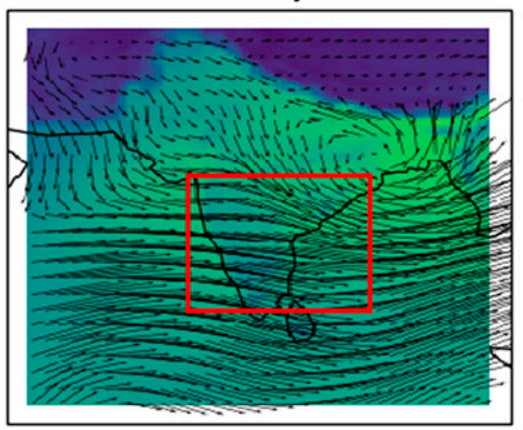

$50 \mathrm{~kg} \mathrm{~m}-1 \mathrm{~s}-1$

(c) day 3 - day 1

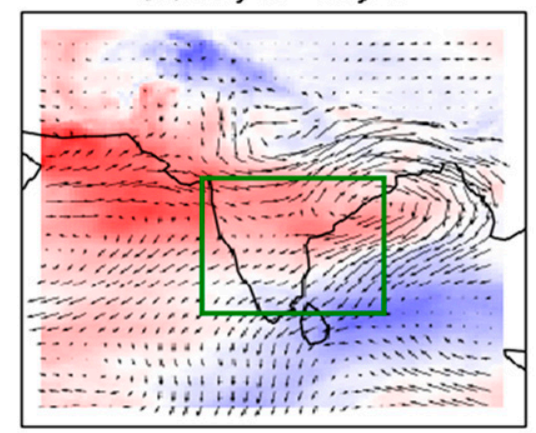

$20 \mathrm{~kg} \mathrm{~m}-1 \mathrm{~s}-1$ (b) day 1 - day 0

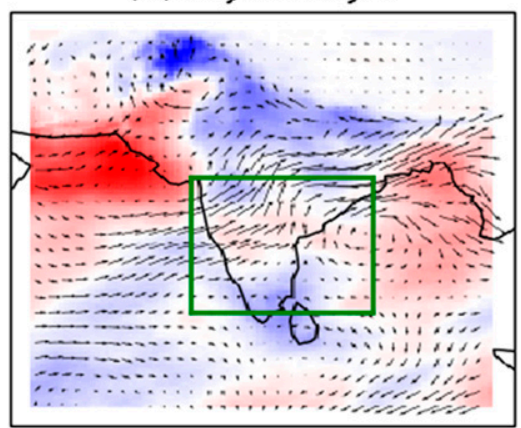

$20 \mathrm{~kg} \mathrm{~m}-1 \mathrm{~s}-1$

(d) day 5 - day 3

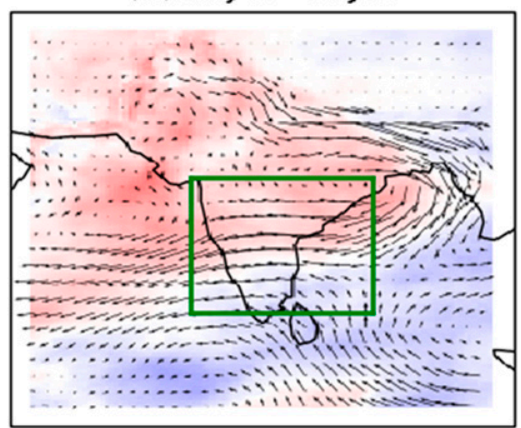

$20 \mathrm{~kg} \mathrm{~m}-1 \mathrm{~s}-1$
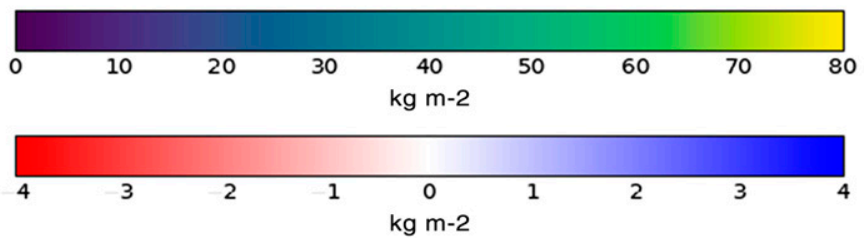

FIG. 11. Total column moisture $\int_{0}^{P_{s}} q\{\tau\} d p / g$, overlaid with moisture flux vectors $\int_{z_{b}}^{\infty}[q\{0\} V\{\tau\}(d p / d z)\{0\} d z] / g$ (i.e., holding the humidity field constant at its analysis value while allowing the velocity field to vary with forecast lead time, so relevant to the quantity $\mathbb{S}^{u}$ defined in the text). (a) The analysis $(\tau=0)$ value, and biases between the two values of $\tau$ denoted in the panel title are shown in the other three panels, that is, the bias that develops during (b) period I, (c) period II, and (d) period III. Note that the humidity is integrated upward from the surface whereas the moisture fluxes are integrated upward from $z_{b}=1.1 \mathrm{~km}$.

were identified by Krishnamurti et al. (2010) as being partly responsible for dry spells in the Indian monsoon. It is possible that the MetUM is simulating these dry intrusions too strongly, leading to too-dry air coming from the northwest that erroneously suppresses the convection in the model. The air over the northwest of India was identified by Pathak et al. (2017) as making a relatively small contribution of moisture to the monsoon rainfall, but possibly enough that if its moisture content is heavily reduced this could make a significant contribution to the reduction in rainfall seen in the MetUM.

The flow entering the box from the Arabian Sea to the west and southwest appears to originate in the western and southern Indian Ocean; these regions have previously been identified as the most important moisture sources for the Indian monsoon (Pathak et al. 2017). Sahana et al. (2019) showed that inaccurate representation of these moisture sources is partly responsible for the Indian monsoon dry bias in CFSv2, a coupled model used by the National Centers for Environmental Prediction for seasonal forecasting. It is apparent from Figs. 1 and 11 that the air in the equatorial Indian Ocean directly to the south of India is too moist and produces too much rainfall in the MetUM. However, this region is identified by Pathak et al. (2017) and Sahana et al. (2019) as being a less important moisture source for the Indian monsoon, and this appears 
from Figs. 1 and 11 to be also the case for shorter time scales. Indeed, there is some evidence that moistening in this region is related to moisture being diverted away from the peninsular region, at least during period II.

\section{f. Horizontal structure of wind speed field and biases}

The variation of moisture flux vectors due to wind speed $\left(\int S d p\right)$ is also shown in Fig. 11. These were calculated by taking the wind velocity at a given forecast lead time, multiplying by the humidity field at analysis time and integrating vertically above $z_{b}$. In this way, they are relevant to the quantity $\mathbb{S}^{u}$. Another physical interpretation is that Fig. 11 shows the evolution of the wind vectors, but weighted toward air that is more humid at analysis time.

The westerly flow is clear to see in Fig. 11a, and the effect of this flow is to transport moisture into the box from the west and out of the box to the east. As discussed in the previous subsection, this moisture comes from two sources: air coming from the southwest of the box (which would be expected to be moister), and air coming from the northwest of the box (which would be expected to be drier). The westerly flow also undulates, and the effect of this on the southern side of the box is that it transports moisture out of the box farther west and back into the box farther east. The moisture flux is also characterized by cyclonic flow to the northeast of India, which may be associated with the monsoon trough or the passage of monsoon depressions.

The reduction in wind flow from the western side of the box also makes an important contribution to the drying of the box leading to reduced rainfall in the NWP forecast. This only manifests itself after approximately 3 days (i.e., during period III), suggesting that it could be due to errors farther upstream, over the Arabian Sea. This connection has been presented in previous work on longer time scales. Levine and Martin (2018) used a set of regional climate model simulations with differing lateral boundary locations to show that the most significant regions of influence on the biases around the Indian Peninsula were those to the south and to the west. Further, it was shown by Bush et al. (2015) that increasing the entrainment rate in the MetUM over the equatorial Indian Ocean (and thereby suppressing convection and alleviating the moist bias over that region) leads to an enhanced southwesterly flow (i.e., reducing the wind bias) and a reduction in the dry bias over India. Willetts et al. (2017) also showed that rainfall over India could be increased by using a convection-permitting model, and that this is partly achieved by increasing the flow of moist air from the Arabian Sea into India, and Chakraborty and Agrawal (2017) showed that an earlier monsoon onset tends to coincide with a stronger low-level jet over the Arabian Sea. Roxy et al. (2017) showed that extreme rainfall events are often related to variability in moisture from the Arabian Sea.
The moisture flux exhibits an anticyclonic bias centered near the eastern edge of the box, which is present for all three periods but shifts northward as the forecast develops. Its effect near the beginning of the forecast is to advect less air in through the northern side of the box, while later in the forecast its effect is to advect less air out through the eastern side of the box. It is possible that this anticyclonic bias corresponds to a weaker monsoon trough, which would lead to a reduction in rainfall overall. A climatological anticyclonic bias was identified by Martin and Levine (2012) and Levine and Martin (2018) in climate simulations, although the positioning of the bias was not the same as in our investigation. Indeed, we have shown that the location of this bias changes as the forecast develops; it also is possible that it would be in a different location in a different monsoon year. Bush et al. (2015) showed that this anticyclonic bias could be reduced by increasing the entrainment rate over the equatorial Indian Ocean, a change that, as mentioned above, also reduced the dry bias over India.

There is a northerly bias during period II on the southern side of the box, which could be indicative of divergent flow toward the equatorial Indian Ocean, where the model produces too much rainfall (Fig. 1). During period III the southern side of the box is near a saddle point in a somewhat complex bias flow, and the northerly bias here seems to be contingent on the precise location of the saddle point. This suggests that correctly simulating smaller-scale features of the flow is important for capturing the flux through the southern edge of the box correctly.

\section{Conclusions}

We have demonstrated in this study that the longstanding summer dry bias over India, seen in climate simulations using the Met Office Unified Model (MetUM), is also partially present in NWP forecasts using the same model. Although there is sometimes more rainfall in the NWP forecasts than observations up to a few days, the NWP forecasts always exhibit a drying tendency over their 5-day length, and this is the case for both the GA3 configuration and the GA6 configuration.

We have analyzed the moisture budget in the NWP forecasts for 2012, focusing on a region over southern India for which the dry bias is worst in both climate simulations and NWP forecasts. Its development with forecast lead time can be separated into three distinct periods:

- During the first day (period I), the moisture flux entering the region and the rainfall are roughly constant, but the individual budget terms vary considerably, as the forecast "spins up" from its analysis.

- During days 1-3 (period II), a steady reduction in the moisture flux coincides with a steady, but slightly more 
gradual, reduction in precipitation, so that the region dries slightly during this period.

- During days 3-5 (period III), the reduction in moisture flux entering the box tails off, while the rainfall continues to decrease at a similar rate to in period II, so that the drying of the box continues but slows down.

In this study we have identified and quantified different sources of Indian monsoon negative rainfall bias in MetUM NWP forecasts, some of which relate to biases previously identified for longer time scale simulations. In particular:

- A reduction in the moisture-carrying wind speed into the west of the region appears from day 3 of the forecast. This provides further evidence that improving the simulation over the Arabian Sea would help to increase rainfall over India.

- The air entering the region from the west is also too dry, and this is the case from very early in the forecast. This is associated with a drying of the air over the northern Arabian Sea. It is not clear what causes this drying initially but it is made worse by a reduction in the flow of moist air from farther south and west, as the forecast develops.

- This drying also applies to already very dry air entering the region from the northwest of India. Improving how the MetUM handles dry intrusions from the northwest may therefore contribute to reducing the dry bias over India, although it is not clear whether this error would continue to be significant in longer model simulations. This may be the same phenomenon as the previous error, with the drying simply spreading southward. Note that this dry air to the northwest of India is advected into the region considered in this study (i.e., southward then eastward) and not directly eastward into northern India (see Fig. 11). This could help to explain why a reduction in rainfall is seen over southern India during the first two days of the forecast, but not over northern India.

- We have provided further evidence of an anticyclonic bias in the wind flow over India. This has a mixed effect on the overall moisture budget, but correcting this would certainly have scope for improving the dry bias.

In general, the errors seem to be more important above the boundary layer than within it, suggesting that improvements to how the MetUM convection scheme handles convective plumes may have a significant impact on the simulated rainfall over India. This has previously been suggested by Bush et al. (2015), who showed that modifying the entrainment rate in the MetUM convection scheme can lead to increased rainfall over India over longer time scales. It is also clear that the short-term drying is not driven significantly by errors in the land surface, as the upward moisture flux at the surface does not change significantly with forecast lead time.
However, there is a small but steady reduction in this quantity when the calculation is restricted to land points, which is offset by an initial, but shorter-lived, increase over ocean points, so feedbacks involving surface evaporation may become more important at longer time scales if this reduction over land points continues further into the forecast. Indeed, Devanand et al. (2018) showed that improving the representation of the Himalayas and land surface processes was effective in improving a similar dry bias seen in the CFSv2 model (see also section 3e and Sahana et al. 2019).

\section{Suggestions for future work}

We have confined this study to looking at the mean flux terms over most of the monsoon season as a whole, and future work will investigate how these terms vary as the monsoon progresses. In particular, we shall determine whether it is possible to identify relatively short periods within the monsoon, which account for a relatively large amount of the overall negative rainfall bias. If this is the case, then it will be possible to run relatively inexpensive further simulations for just these short periods, and to test the likely effects of model changes on the dry bias in the MetUM. Similarly, we have been careful to eliminate the effects of the diurnal cycle on our overall budget, but it would also be interesting to carry out an analysis on shorter time scales and to investigate how the diurnal cycle varies as the forecast progresses.

Having shown that the drying tendency is common to all years of a 6-yr period, we have focused on a single year as representative of the recent past. We are currently working on repeating the full analysis for all the years 2011-18, in order to investigate to what extent conclusions hold for other years (in particular those with a different model version), and to enable an enhanced significance testing of the conclusions arrived at in this study. Initial results suggest that the decrease in moisture flux into the region from around day 3 , as well as the drying of the air to the west and northwest of the region, is seen in other recent years. Some other years show evidence of an anticyclonic bias, although in varying locations meaning it has a varying effect on the moisture fluxes, particularly into the northern side of the region.

The detailed moisture budget investigation, carried out in this study for weather forecasts, could also be applied to climate simulations. This would involve a somewhat different approach, since there would only be a single simulation for the whole period, rather than several shorter, overlapping simulations, and the simulations would have to be compared with, for example, reanalysis datasets, instead of against the same model analysis. However, it would be useful to investigate how the dry bias, and the moisture budget terms, develop on the longer time scales of a climate simulation, and this might further inform the discussion of similarities and differences in the dry bias between climate simulations and weather forecasts using the MetUM. 
It will be interesting to carry out a similar analysis for other regions, particularly that to the south of India, where there is a wet bias, and over northern India, where the biases in the weather and climate simulations are different. For northern India, initial analysis suggests that there is a similar steady decrease in total moisture flux into the region (to that for southern India), but that the rainfall increases initially before steadily decreasing later in the forecast. This rainfall behavior is also seen over southern India in other recent years (see Fig. 2), so extending the analysis to these years may clarify the comparison between the climate simulations and weather forecasts.

The effects of initial conditions on the dry bias should also be considered. It is possible that a model captures the monsoon system correctly, but incorrect initial conditions cause it to develop toward an equilibrium state that produces less rainfall than the real atmosphere. We have conducted forecast experiments for 2012, similar to those analyzed in this study, with different initial conditions, and analysis of these experiments will also form the basis of a future study.

Acknowledgments. We thank Prince Xavier, Sean Milton, Mike Cullen, and John Marsham for discussion and comments on the manuscript. The 30-yr climate simulations using the MetUM at GA6 were carried out by Paul Ernshaw. R. J. Keane was funded by the INCOMPASS project (Interaction of Convective Organization and Monsoon Precipitation, Atmosphere, Surface and Sea). D. J. Parker was funded by INCOMPASS (NE/L013843/1). The work of D. J. Parker was also supported by a Royal Society Wolfson Research Merit Award (2014-18). G. M. Martin was supported by the Met Office Hadley Centre Climate Programme funded by BEIS and DEFRA. We thank three anonymous reviewers, whose suggestions have greatly improved the quality and clarity of the manuscript.

\section{APPENDIX}

\section{Technical Details}

\section{a. Correction factors}

We use four forecasts per day in order to sample the diurnal cycle sufficiently. These are initiated at 0000, 0600, 1200 , and 1800 UTC. However, two of the forecasts are only available out to $60 \mathrm{~h}$, which means that after this time, any averaged quantity $x$ will be evaluated using only the two remaining forecasts and this could introduce a bias into the forecast average since only two points in the diurnal cycle are sampled. To correct for this, we use the forecasts up to $60 \mathrm{~h}$ to see what bias $k$ would be introduced if the 0600 and 1800 UTC forecasts had been unavailable and only the 0000 and 1200 UTC forecasts were used. We define $x_{\mathrm{XXXX}}$ as the average of all forecasts initialized at XXXX UTC, $x_{4}$ as the estimate of $x$ based on using all available forecasts, and $x_{2}$ as the estimate of $x$ based on only using the 0000 and 1200 UTC forecasts. Then $x_{2}=x_{4}+k$, with

$$
\begin{aligned}
& x_{2} \equiv\left(x_{0000}+x_{1200}\right) / 2, \quad \text { and } \\
& x_{4} \equiv\left(x_{0000}+x_{0600}+x_{1200}+x_{1800}\right) / 4 .
\end{aligned}
$$

In practice $k$ varies with forecast lead time $\tau$, but it is a reasonable approximation to treat it as a constant. This is demonstrated by Fig. A1, where we have plotted various moisture flux terms calculated using only the 0000 and 1200 UTC forecasts and using only the 0600 and 1800 UTC forecasts. It is clear that, although the difference between each pair is not constant, each pair does follow a very similar variation with forecast lead time and assuming a constant offset is valid. We therefore estimate $k$ as

$$
k \approx \overline{\left(x_{0000}+x_{1200}\right) / 2-\left(x_{0000}+x_{0600}+x_{1200}+x_{1800}\right) / 4},
$$

where the bar denotes an average over the period between 0 and $\tau_{60}=60 \mathrm{~h}$. This is then subtracted off the later forecasts to estimate what the quantity would have been had all four forecasts been available. In summary:

$$
\begin{aligned}
x\left(\tau \leq \tau_{60}\right)= & x_{4}=\left(x_{0000}+x_{0600}+x_{1200}+x_{1800}\right) / 4, \\
x\left(\tau>\tau_{60}\right)= & x_{2}-k \\
= & \left(x_{0000}+x_{1200}\right) / 2 \\
& -\overline{\left(x_{0000}+x_{1200}-x_{0600}-x_{1800}\right) / 4}
\end{aligned}
$$

The exception to this was the surface upward moisture flux $\mathbb{E}$, which was not available at all after $60 \mathrm{~h}$. Instead, we used the surface latent heat flux $h$ (which is available averaged over the previous $6 \mathrm{~h}$ ) to define

$$
\mathbb{L}=\iint \frac{h}{l} d^{2} A,
$$

where $l$ is the latent heat of vaporization of water. Then $\mathbb{E}\left(\tau \leq \tau_{60}\right)$ was defined as in Eq. (A4) up to $60 \mathrm{~h}$, and after $60 \mathrm{~h}$ was defined as

$$
\begin{aligned}
\mathbb{E}\left(\tau>\tau_{60}\right)= & \left(\mathbb{L}_{0000}+\mathbb{L}_{1200}\right) / 2 \\
& -\overline{\left(\mathbb{L}_{0000}+\mathbb{L}_{1200}\right) / 2-\left(\mathbb{E}_{0000}+\mathbb{E}_{0600}+\mathbb{E}_{1200}+\mathbb{E}_{1800}\right) / 4} .
\end{aligned}
$$




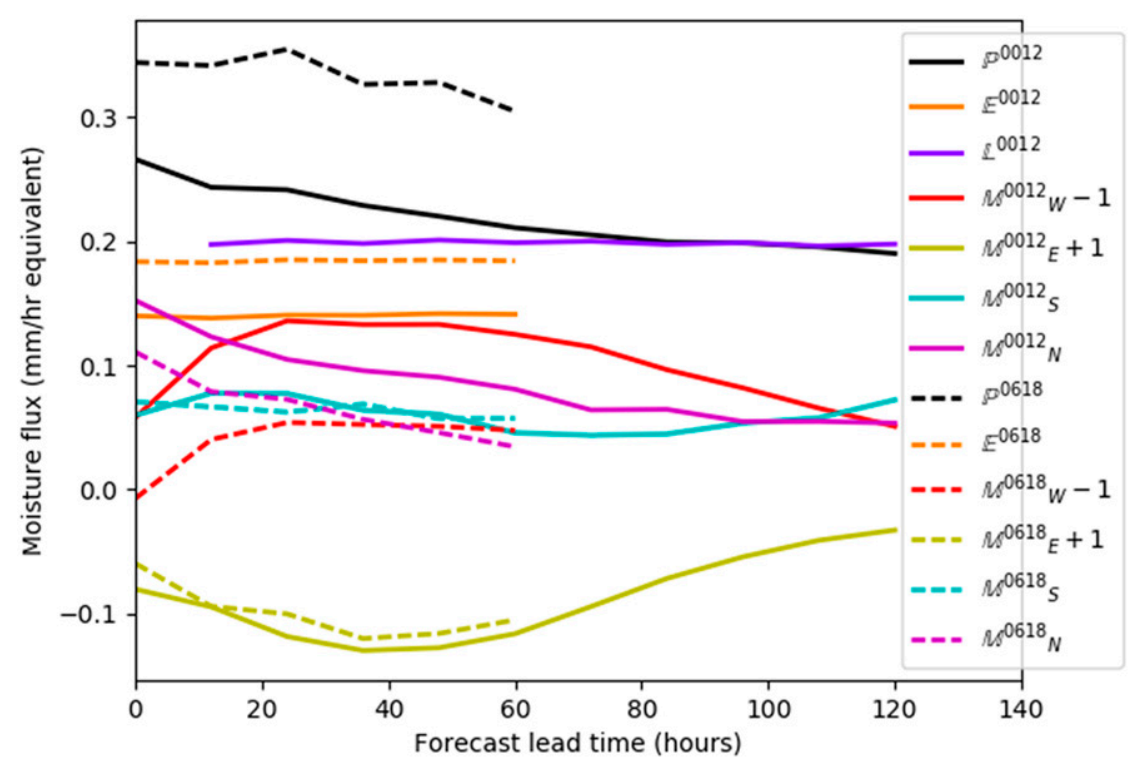

FIG. A1. Behavior of different moisture budget terms as a function of lead time, separated into forecasts starting at 0000 and $1200 \mathrm{UTC}\left(x^{0012}\right)$ and starting at 0600 and 1800 UTC $\left(x^{0618}\right.$, only available up to $60 \mathrm{~h}$ ). The behavior of each of the two sets is similar, suggesting that a constant offset can be used to calibrate the $x^{0012}$ forecasts after $60 \mathrm{~h}$.

\section{b. Instantaneous rainfall}

To be consistent with other quantities, we have used instantaneous rainfall throughout the moisture budget analysis. It could be argued that, for such an intermittent field as rainfall, longer time accumulations are required. To check this, we plot in Fig. A2 the 12-h accumulated and instantaneous rainfall together, along with the resulting total flux term for each quantity. This gives some idea of the uncertainty involved in using instantaneous rainfall:

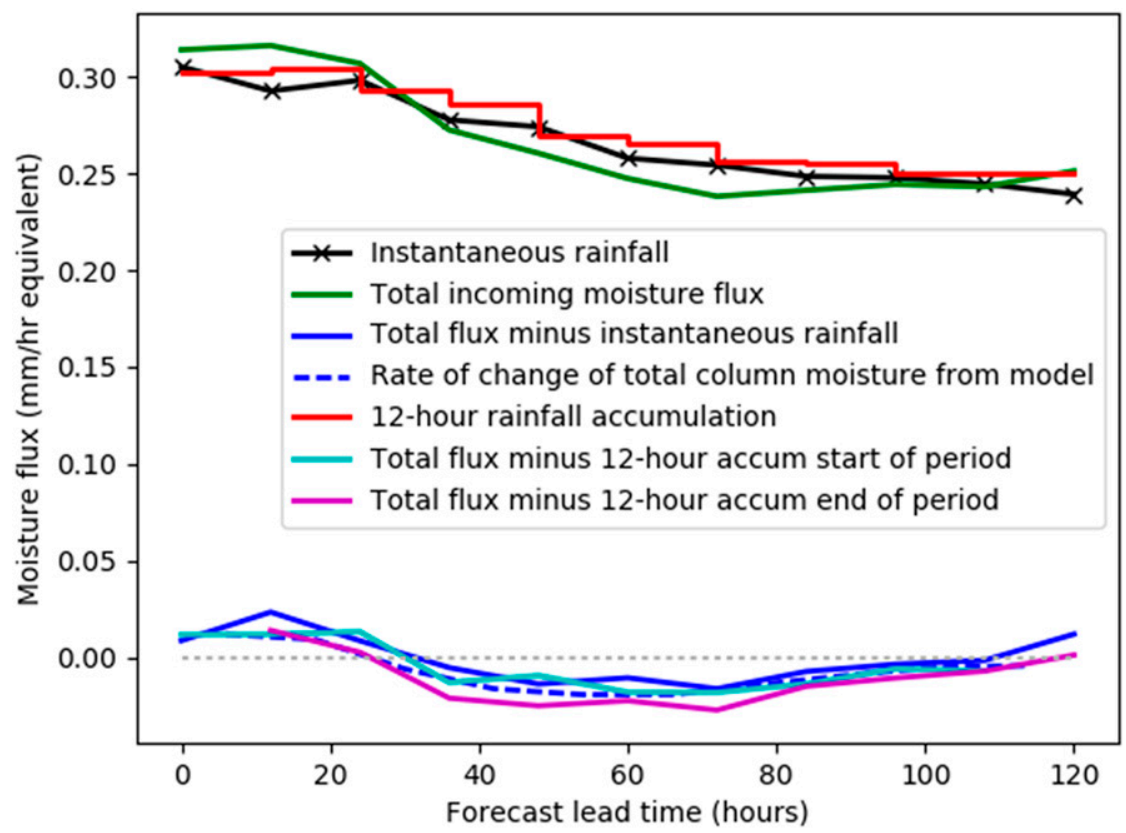

FIG. A2. Comparison of instantaneous rainfall with 12-h accumulated rainfall, and the effect of using each quantity on the overall moisture budget. The two total flux terms for the accumulated rainfall represent assigning the accumulated value to the beginning or the end of the 12 -h period. 
note that the 12-h accumulation is not a better quantity to use because it samples parts of the diurnal cycle that are not sampled by the other quantities in the moisture budget. It is clear from Fig. A2 that the overall conclusions from this study, relating to the rainfall field, would not be affected if a longer accumulated period was used for the rainfall.

\section{c. Calculation of significance intervals}

The significance intervals were calculated using a simple bootstrapping method, based on determining the sensitivity of the calculation to the precise period used. For each spatially averaged quantity $x$, the data were divided into pairs of forecasts, one starting at 0000 or 1200 UTC (lasting the full $120 \mathrm{~h}$ ) and the other $6 \mathrm{~h}$ later (lasting 60h). Equations (A4), (A5), and (A7) were then applied, with the 0000 or 1200 UTC forecast taking the role of $\left(x_{0000}+x_{1200}\right) / 2$ and the 0600 or 1800 UTC forecast taking the role of $\left(x_{1200}+x_{1800}\right) / 2$, to produce a set of 172 forecasts, for each quantity and for each lead time.

The bootstrapping was applied by constructing, for each lead time, 10000 sequences of 172 forecasts, each randomly selected from the 172 values available (i.e., with replacement, so it was possible to select the same forecast more than once in any given sequence). The mean value of $x$ was then taken over each of the 10000 sequences, to produce 10000 estimates of $x$. These estimates were sorted and the 250th-highest estimate was taken as the upper bound and the 9750th-highest estimate as the lower bound. In this way, an estimate of the $95 \%$ significance interval was produced.

\section{REFERENCES}

Adler, R. F., and Coauthors, 2003: The Version-2 Global Precipitation Climatology Project (GPCP) monthly precipitation analysis (1979-present). J. Hydrometeor., 4, 1147-1167, https://doi.org/ 10.1175/1525-7541(2003)004<1147:TVGPCP > 2.0.CO;2.

Birch, C. E., D. J. Parker, J. H. Marsham, D. Copsey, and L. GarciaCarreras, 2014: A seamless assessment of the role of convection in the water cycle of the west African monsoon. J. Geophys. Res. Atmos., 119, 2890-2912, https://doi.org/10.1002/2013JD020887.

Brown, A., S. Milton, M. Cullen, B. Golding, J. Mitchell, and A. Shelly, 2012: Unified modeling and prediction of weather and climate: A 25-year journey. Bull. Amer. Meteor. Soc., 93, 1865-1877, https://doi.org/10.1175/BAMS-D-12-00018.1.

Bush, S. J., A. G. Turner, S. J. Woolnough, G. M. Martin, and N. P. Klingaman, 2015: The effect of increased convective entrainment on Asian monsoon biases in the MetUM general circulation model. Quart. J. Roy. Meteor. Soc., 141, 311-326, https://doi.org/ 10.1002/qj.2371.

Chakraborty, A., and S. Agrawal, 2017: Role of west Asian surface pressure in summer monsoon onset over central India. Environ. Res. Lett., 12, 074002, https://doi.org/10.1088/1748-9326/aa76ca.

Dee, D. P., and Coauthors, 2011: The ERA-Interim reanalysis: Configuration and performance of the data assimilation system. Quart. J. Roy. Meteor. Soc., 137, 553-597, https://doi.org/10.1002/qj.828.
Devanand, A., M. K. Roxy, and S. Ghosh, 2018: Coupled landatmosphere regional model reduces dry bias in Indian summer monsoon rainfall simulated by CFSv2. Geophys. Res. Lett., $\mathbf{4 5}$, 2476-2486, https://doi.org/10.1002/2018GL077218.

Gadgil, S., and J. Srinivasan, 2012: Monsoon prediction: Are dynamical models getting better than statistical models. Curr. Sci., 103, 257-259.

Hou, A. Y., and Coauthors, 2014: The Global Precipitation Measurement Mission. Bull. Amer. Meteor. Soc., 95, 701-722, https:// doi.org/10.1175/BAMS-D-13-00164.1.

Huffman, G. J., and Coauthors, 2007: The TRMM Multisatellite Precipitation Analysis (TMPA): Quasi-global, multiyear, combinedsensor precipitation estimates at fine scales. J. Hydrometeor., $\mathbf{8}$, 38-55, https://doi.org/10.1175/JHM560.1.

, R. F. Adler, D. T. Bolvin, and E. J. Nelkin, 2010: The TRMM Multi-Satellite Precipitation Analysis (TMPA). Satellite Rainfall Applications for Surface Hydrology, Springer, 3-22, https:// doi.org/10.1007/978-90-481-2915-7_1.

Johnson, S. J., and Coauthors, 2016: The resolution sensitivity of the South Asian monsoon and Indo-Pacific in a global $0.35^{\circ}$ AGCM. Climate Dyn., 46, 807-831, https://doi.org/10.1007/ s00382-015-2614-1.

- A. Turner, S. Woolnough, G. Martin, and C. MacLachlan, 2017: An assessment of Indian monsoon seasonal forecasts and mechanisms underlying monsoon interannual variability in the Met Office GloSea5-GC2 system. Climate Dyn., 48, 1447-1465, https://doi.org/10.1007/s00382-016-3151-2.

Joshi, M., and S. C. Kar, 2016: Value-added quantitative mediumrange rainfall forecasts for the BIMSTEC region. Meteor. Appl., 23, 491-502, https://doi.org/10.1002/met.1573.

Klocke, D., and M. J. Rodwell, 2014: A comparison of two numerical weather prediction methods for diagnosing fast-physics errors in climate models. Quart. J. Roy. Meteor. Soc., 140, 517-524, https://doi.org/10.1002/qj.2172.

Krishnamurti, T. N., A. Thomas, A. Simon, and V. Kumar, 2010: Desert air incursions, an overlooked aspect, for the dry spells of the Indian summer monsoon. J. Atmos. Sci., 67, 3423-3441, https://doi.org/10.1175/2010JAS3440.1.

Kumar, A., and Coauthors, 2017: Block level weather forecast using direct model output from NWP models during monsoon season in India. Mausam, 68, 23-40.

Levine, R. C., and A. G. Turner, 2012: Dependence of Indian monsoon rainfall on moisture fluxes across the Arabian Sea and the impact of coupled model sea surface temperature biases. Climate Dyn., 38, 2167-2190, https://doi.org/10.1007/ s00382-011-1096-z.

_ , and G. M. Martin, 2018: On the climate model simulation of Indian monsoon low pressure systems and the effect of remote disturbances and systematic biases. Climate Dyn, 50, 47214743, https://doi.org/10.1007/s00382-017-3900-x.

— A. G. Turner, D. Marathayil, and G. M. Martin, 2013: The role of northern Arabian Sea surface temperature biases in CMIP5 model simulations and future projections of Indian summer monsoon rainfall. Climate Dyn., 41, 155-172, https:// doi.org/10.1007/s00382-012-1656-x.

Martin, G. M., and R. C. Levine, 2012: The influence of dynamic vegetation on the present-day simulation and future projections of the South Asian summer monsoon in the HadGEM2 family. Earth Syst. Dyn., 3, 245-261, https:// doi.org/10.5194/esd-3-245-2012.

, S. F. Milton, C. A. Senior, M. E. Brooks, S. Ineson, T. Reichler, and J. Kim, 2010: Analysis and reduction of systematic errors through a seamless approach to modeling 
weather and climate. J. Climate, 23, 5933-5957, https://doi.org/ 10.1175/2010JCLI3541.1.

Mitra, A. K., G. R. Iyengar, V. R. Durai, J. Sanjay, T. N. Krishnamurti, A. Mishra, and D. R. Sikka, 2011: Experimental real-time multi-model ensemble (MME) prediction of rainfall during monsoon 2008: Large-scale medium-range aspects. J. Earth Syst. Sci., 120, 27-52, https://doi.org/10.1007/s12040011-0013-5.

— coupled modelling system. Curr. Sci., 104, 1369-1379.

Parker, D. J., P. Willetts, C. Birch, A. G. Turner, J. H. Marsham, C. M. Taylor, S. Kolusu, and G. M. Martin, 2016: The interaction of moist convection and mid-level dry air in the advance of the onset of the Indian monsoon. Quart. J. Roy. Meteor. Soc., 142, 2256-2272, https://doi.org/10.1002/qj.2815.

Pathak, A., S. Ghosh, J. A. Martinez, F. Dominguez, and P. Kumar, 2017: Role of oceanic and land moisture sources and transport in the seasonal and interannual variability of summer monsoon in India. J. Climate, 30, 1839-1859, https://doi.org/10.1175/ JCLI-D-16-0156.1.

Prakash, S., A. K. Mitra, I. M. Momin, E. N. Rajagopal, S. F. Milton, and G. M. Martin, 2016: Skill of short- to mediumrange monsoon rainfall forecasts from two global models over India for hydro-meteorological applications. Meteor. Appl., 23, 574-586, https://doi.org/10.1002/met.1579.

Ranade, A., A. Mitra, N. Singh, and S. Basu, 2014: A verification of spatio-temporal monsoon rainfall variability across Indian region using NWP model output. Meteor. Atmos. Phys., 125, 43-61, https://doi.org/10.1007/S00703-014-0317-5.

Ringer, M. A., and Coauthors, 2006: Global mean cloud feedbacks in idealized climate change experiments. Geophys. Res. Lett., 33, L07718, https://doi.org/10.1029/2005GL025370.

Rodwell, M. J., and T. N. Palmer, 2007: Using numerical weather prediction to assess climate models. Quart. J. Roy. Meteor. Soc., 133, 129-146, https://doi.org/10.1002/qj.23.

Roxy, M. K., S. Ghosh, A. Pathak, R. Athulya, M. Mujumdar, R. Murtugudde, P. Terray, and M. Rajeevan, 2017: A threefold rise in widespread extreme rain events over central India. Nat. Commun., 8, 708, https://doi.org/10.1038/S41467-017-00744-9.
Sahana, A. S., A. Pathak, M. K. Roxy, and S. Ghosh, 2019: Understanding the role of moisture transport on the dry bias in Indian monsoon simulations by CFSv2. Climate Dyn., 52, 637651, https://doi.org/10.1007/S00382-018-4154-Y.

Sperber, K. R., H. Annamalai, I.-S. Kang, A. Kitoh, A. Moise, A. Turner, B. Wang, and T. Zhou, 2013: The Asian summer monsoon: An intercomparison of CMIP5 vs. CMIP3 simulations of the late 20th century. Climate Dyn., 41, 2711-2744, https://doi.org/10.1007/s00382-012-1607-6.

Walters, D. N., and Coauthors, 2011: The Met Office Unified Model Global Atmosphere 3.0/3.1 and JULES Global Land 3.0/3.1 configurations. Geosci. Model Dev., 4, 919-941, https:// doi.org/10.5194/gmd-4-919-2011.

- , and Coauthors, 2017: The Met Office Unified Model Global Atmosphere 6.0/6.1 and JULES Global Land 6.0/6.1 configurations. Geosci. Model Dev., 10, 1487-1520, https://doi.org/ 10.5194/gmd-10-1487-2017.

Willetts, P. D., J. H. Marsham, C. E. Birch, D. J. Parker, S. Webster, and J. Petch, 2017: Moist convection and its upscale effects in simulations of the Indian monsoon with explicit and parametrized convection. Quart. J. Roy. Meteor. Soc., 143, 1073-1085, https://doi.org/10.1002/qj.2991.

Yanai, M., S. Esbensen, and J.-H. Chu, 1973: Determination of bulk properties of tropical cloud clusters from large-scale heat and moisture budgets. J. Atmos. Sci., 30, 611-627, https://doi.org/ 10.1175/1520-0469(1973)030<0611:DOBPOT>2.0.CO;2.

Zangvil, A., D. H. Portis, and P. J. Lamb, 2001: Investigation of the large-scale atmospheric moisture field over the midwestern United States in relation to summer precipitation. Part I: Relationships between moisture budget components on different timescales. J. Climate, 14, 582597, https://doi.org/10.1175/1520-0442(2001)014<0582: IOTLSA $>2.0 . \mathrm{CO} ; 2$.

,-- , and,- 2004 : Investigation of the large-scale atmospheric moisture field over the midwestern United States in relation to summer precipitation. Part II: Recycling of local evapotranspiration and association with soil moisture and crop yields. J. Climate, 17, 3283-3301, https://doi.org/10.1175/ 1520-0442(2004)017<3283:IOTLAM>2.0.CO;2. 